\title{
Hydrological tracers for assessing transport and dissipation processes of pesticides in a model constructed wetland system
}

\author{
Elena Fernández-Pascual ${ }^{1}$, Marcus Bork ${ }^{1,2}$, Birte Hensen $^{3}$, and Jens Lange ${ }^{1}$ \\ ${ }^{1}$ Hydrology, Faculty of Environment and Natural Resources, University of Freiburg, Freiburg, Germany \\ ${ }^{2}$ Soil Ecology, Faculty of Environment and Natural Resources, University of Freiburg, Freiburg, Germany \\ ${ }^{3}$ Institute of Sustainable and Environmental Chemistry, Leuphana University Lüneburg, Lüneburg, Germany
}

Correspondence: Elena Fernández-Pascual (elena.fernandez@hydrology.uni-freiburg.de)

Received: 11 January 2019 - Discussion started: 6 February 2019

Revised: 24 October 2019 - Accepted: 28 October 2019 - Published: 8 January 2020

\begin{abstract}
Studies that have used hydrological tracers to investigate the fate and transport of pesticides in constructed wetlands have often considered such systems as a "black box". Consequently, internal temporal and spatial mechanisms that dominate pesticide transport and dissipation (e.g., sorption, transformation and plant uptake) are still not fully understood. Here we present a novel approach that combines the use of tracers with different sorptive and reactive properties - i.e., bromide $\left(\mathrm{Br}^{-}\right)$, uranine (UR) and sulforhodamine B (SRB) - with high vertical resolution sampling and monitoring to evaluate transport and dissipation processes of three selected pesticides (boscalid, penconazole and metazachlor) inside a model constructed wetland system on a long-term basis and detailed spatial scale. Moreover, the influence of vegetation and alternating different hydrologic conditions on transport and dissipation processes was evaluated by comparing a vegetated with a non-vegetated section and by alternating periods of saturation and drying. Breakthrough curves obtained at different sampling depths pointed out that the solutes were not equally distributed within the constructed wetland. Data revealed that a higher mass of solutes was transported to the vegetated part of the uppermost layer, which was associated with possible lateral transport at or near the surface and/or a shortcut effect produced by the roots. In contrast, the middle layers showed retardation, most likely due to the presence of water-filled pores before the injections and low pore connectivity in the vicinity of the sampling ports. The strong temporal and spatial correlation found between $\mathrm{Br}^{-}$, UR and metazachlor indicated that transport was the dominant process for these solutes. Conversely, SRB, boscalid and penconazole most likely under-
\end{abstract}

went sorption, as evidenced by their absence in the middle layers, the rapid decrease in their concentrations after the injections and the gradual increase in accumulated mass recovery at the outlet. The overall tracer mass balance allowed us to identify three dissipation pathways: sorption, transformation and plant uptake. The detection of metazachlor transformation products (TPs) confirmed the contribution of transformation to metazachlor dissipation, whereas no TPs for boscalid and penconazole were detected; however, their transformation could not be ruled out in the present study. Hot spots of sorption and transformation were found in the uppermost layer, whereas hot moments were detected at the beginning of the experiment for sorption and after promoting aerated conditions for transformation. The use of hydrological tracers coupled with high vertical resolution sampling and monitoring proved to provide valuable information about the transport vectors and dissipation processes of pesticides inside a constructed wetland. This study represents a first approximation, and further experiments need to be carried under field conditions in combination with modeling.

\section{Introduction}

Pesticides are widely used to protect crops and increase their yields around the world. It is well known that their use might result in ecotoxicological effects in nontarget environments (Stehle and Schulz, 2015). Chemical analysis performed in the waters of European countries has revealed that pesticides are often detected in surface waters (Müller et al., 2002; von der Ohe et al., 2011; Casado et al., 2019). This prob- 
lem becomes even more severe if the incomplete degradation of pesticides leads to a large number of transformation products (TPs), as the behavior of these products is often unknown and their toxicity or persistence may be greater than those of the parent compounds. In fact, the presence of TPs in water bodies has already been reported in numerous studies (Kolpin et al., 2004; Eurostat, 2012; Reemtsma et al., 2013).

Buffer zones have emerged as a measure for controlling water pollution. Constructed wetlands are one example of buffer zones, where the removal of pesticides takes place. Constructed wetlands are designed to simulate and take advantage of processes that occur in natural wetlands (Vymazal, 2005), such as sedimentation, photolysis, hydrolysis, adsorption, microbial degradation and plant uptake (Vymazal and Březinová, 2015). In these systems vegetation plays an essential role in promoting sedimentation by reducing the current velocities of the water (Petticrew and Kalff, 1992), providing a substrate for microorganisms in the roots and rhizomes (Hofmann, 1986), and creating oxidized conditions in the roots that stimulate aerobic decomposition (Brix, 1997). Removal processes in constructed wetlands may also be promoted via intermittent water flows by enhancing aeration and providing different redox conditions that are suitable for the growth of different microbiological communities (Ong et al., 2010; Maillard et al., 2011; Fan et al., 2013).

The mitigation capacities of buffer zones have recently been studied by using hydrological tracers as a low-cost approach. In this context, fluorescent tracers - e.g., uranine (UR) and sulforhodamine B (SRB) - have often been chosen to study the transport and fate of pesticides because they are organic, non-toxic molecules and can easy to be analyzed. For instance, some authors have used them in wetlands (Passeport et al., 2010; Lange et al., 2011; Durst et al., 2013; Maillard et al., 2016) and farm ditches (Dollinger et al., 2017). However, in most cases where this approach has been applied, the system under study has been treated as a "black box" where the timescales were typically limited to the time spans of the tracers' breakthroughs at the system outlet. Hence, internal temporal and spatial mechanisms that dominate pesticide transport and dissipation (e.g., sorption, transformation and plant uptake) are still not fully clear. Moreover, information on the fate and, particularly, the transformation of pesticides inside wetland sediments is still limited.

Therefore, the objectives of this study were as follows: (i) to apply a multi-tracer approach in combination with high vertical resolution sampling and monitoring to identify transport patterns and dissipation processes of three pesticides selected as test substances inside a model constructed wetland system; (ii) to compare the temporal and spatial behavior of the applied tracers with that of the pesticides and evaluate their main dissipation pathways; and (iii) to assess the influence of vegetation and alternating different hydrologic conditions (saturated and unsaturated) on transport and dissipation processes.
Our study is one of the first to look at the solutes behavior inside a constructed wetland on a long-term basis and at a detailed spatial scale. With this experiment, we expect to provide new insights into the potential of hydrological tracers to evaluate the transport and dissipation processes of pesticides. In addition, we seek to extend the knowledge regarding the mitigation capacities of constructed wetlands.

The experiment was conducted in a constructed wetland where one half was planted with two common wetland plants and the other half was left unplanted. The constructed wetland was equipped with a system designed to perform high vertical resolution sampling and monitoring on a long-term basis. Three hydrological tracers were chosen as reference substances according to their reactive nature: bromide $\left(\mathrm{Br}^{-}\right)$ as a non-adsorbing tracer (Whitmer et al., 2000), UR as a photosensitive tracer (Gutowski et al., 2015) that can undergo processes of (bio-)chemical transformation (Lange et al., 2018) and SRB as a highly sorptive tracer (Kasnavia et al., 1999). Three pesticides were selected as test substances according to their different physicochemical properties and frequent detection in a field-based constructed wetland where other studies within the same project were carried out: boscalid (2-chloro-N-(4'-chlorobiphenyl-2-yl) nicotinamide), penconazole ((RS)-1-[2-(2,4-dichlorophenyl) pentyl]-1H-1,2,4-triazole) and metazachlor (2-chloro-N(pyrazol-1-ylmethyl) acet-2',6'-xylidide).

\section{Materials and methods}

\subsection{Chemicals}

The physiochemical properties of the tracers and pesticides are summarized in Table 1. UR was purchased from Simon \& Werner GmbH (CAS-no. 518-47-8), SRB from Waldeck GmbH \& Co KG (CAS-no. 3520-42-1) and $\mathrm{Br}^{-}$was obtained as sodium bromide from Carl Roth GmbH \& Co KG. Boscalid (99.8\%), penconazole (99\%) and metazachlor $(99.7 \%)$ already dissolved in acetonitrile $(99.9 \%)$ were purchased from NEOCHEMA GmbH (Bodenheim, Germany). The analytical standards of boscalid (99.9\%), penconazol (99.1\%), metazachlor (99.6\%) and p-chlorobenzoic acid $(99 \%)$ were purchased from SigmaAldrich Chemie GmbH (Steinheim, Germany). 1,2,4Triazole $(99.5 \%)$ was purchased from LGC Standards (Wesel, Germany). Metazachlor-ESA (95\%) and metazachlorOA $(98.8 \%)$, hereafter referred to as "met-ESA" and "metOA", respectively, and the internal standard terbutryn- $\mathrm{d}_{5}$ $(98.5 \%)$ already dissolved in acetonitrile $\left(100 \mu \mathrm{g} \mathrm{mL}^{-1}\right)$ were received from NEOCHEMA GmbH.

The target injection masses of tracers and pesticides for an injection volume of $40 \mathrm{~L}$ were calculated according to Durst et al. (2013). Standard stock solutions of $1 \mathrm{~g} \mathrm{~L}^{-1}$ for UR and SRB and of $10 \mathrm{~g} \mathrm{~L}^{-1}$ for $\mathrm{Br}^{-}$were prepared in MilliQ water. Pesticides $\left(0.1 \mathrm{~g} \mathrm{~L}^{-1}\right)$ dissolved in acetonitrile 

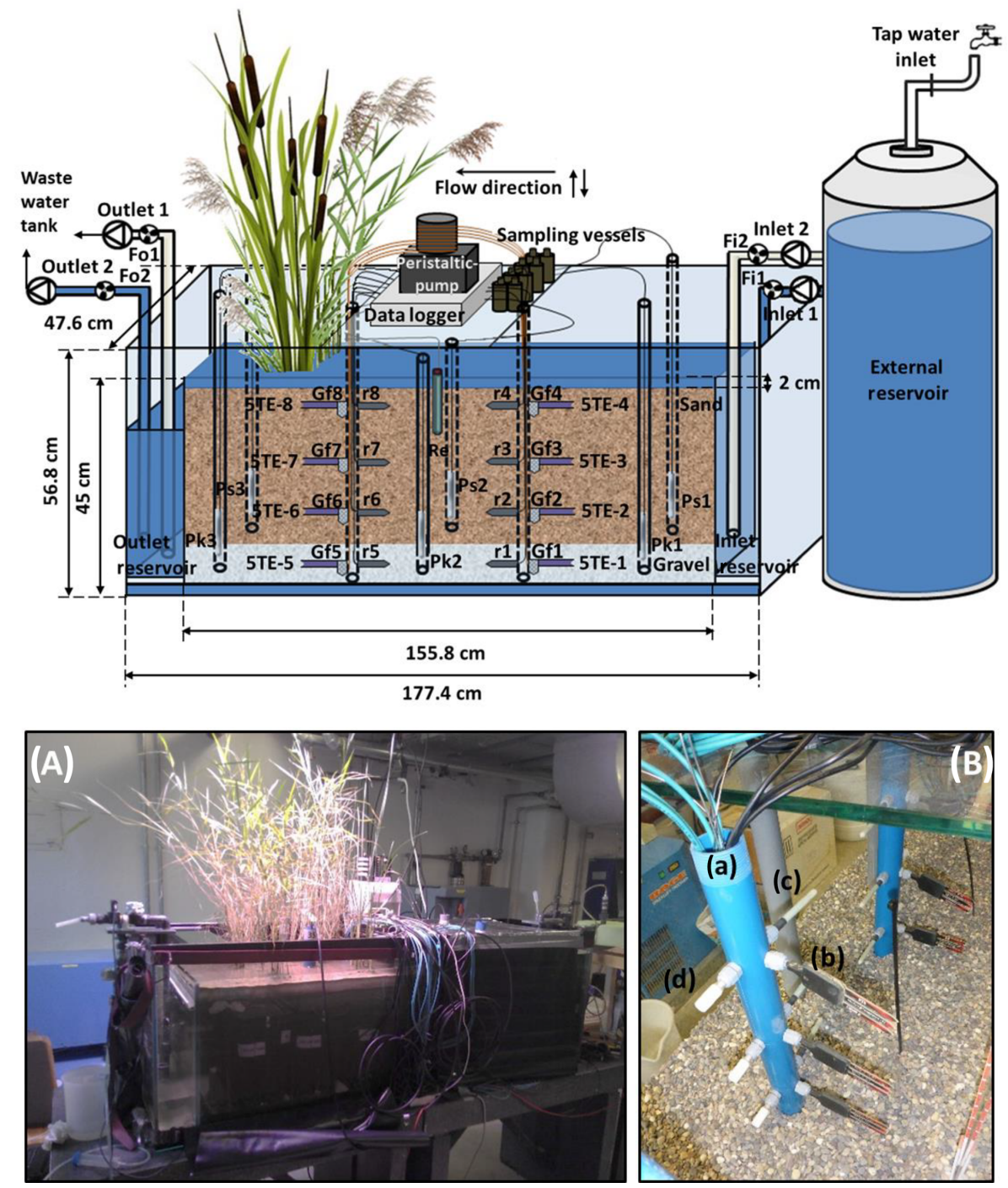

Figure 1. Schematic representation of the model constructed wetland system (not to scale). Fi1 and Fi2 indicate the flowmeters at the inlet; Fo1 and Fo2 indicate the flowmeters at the outlet; $\mathrm{Ps}(\mathrm{n})$ denotes a piezometer in the sand; $\mathrm{Pk}(\mathrm{n})$ denotes a piezometer in the gravel; 5TE-(n) denotes a soil moisture, temperature and electrical conductivity sensor; $r(n)$ denotes a platinum redox electrode; Re is a reference electrode $(\mathrm{Ag}: \mathrm{AgCl}) ; \mathrm{Gf}(\mathrm{n})$ denotes a glass filter. For the piezometers, $n$ indicates the position with respect to the inlet: $n=1$ is close to the inlet, $n=2$ is in the middle of the sediment bed and $n=3$ is close to the outlet. For the sensors installed in the multilevel pipes, $n$ indicates the zone and the depths where they are located: $n=1,2,3$ and 4 refer to the non-vegetated zone at a depth of 39, 27, 15 and $3 \mathrm{~cm}$, respectively; $n=5$, 6,7 and 8 refer to the vegetated zone at a depth of 39,27, 15 and $3 \mathrm{~cm}$, respectively. (A) Front view photograph of the model constructed wetland system. (B) Detail of the multilevel pipes: (a) multilevel pipe in the vegetated zone, (b) a 5TE sensor, (c) a redox electrode and (d) a glass filter.

were directly mixed with the injection solution. The concentration of tracers and pesticides in the injection solution was $100 \mathrm{mg} \mathrm{L}^{-1}, 50$ and $100 \mu \mathrm{g} \mathrm{L}-1$, for sodium bromide, $\mathrm{UR}$ and SRB, respectively, and $50 \mu \mathrm{g} \mathrm{L}^{-1}$ for boscalid, penconazole and metazachlor.

\subsection{Design of the model constructed wetland system}

The model constructed wetland system consisted of a glass tank that was $177.4 \mathrm{~cm}$ long, $47.6 \mathrm{~cm}$ wide and $56.8 \mathrm{~cm}$ deep
(Fig. 1). The system was divided into three parts, two of them inlet and outlet reservoirs located at both ends and separated by two glass walls and a third part located in the middle consisting of the main bed of sediments. The bottom was filled with $10 \mathrm{~cm}$ of gravel (grain size 4-8 $\mathrm{mm}$ ) and topped with $32 \mathrm{~cm}$ of sand (grain size $0.01-2 \mathrm{~mm}$ ). The characteristics of the system are given in Table 2a. One half of the system was left unplanted, while the other half was planted with two species of widespread and ubiquitous wetland plants (Typha latifolia and Phragmites australis) with an average initial 


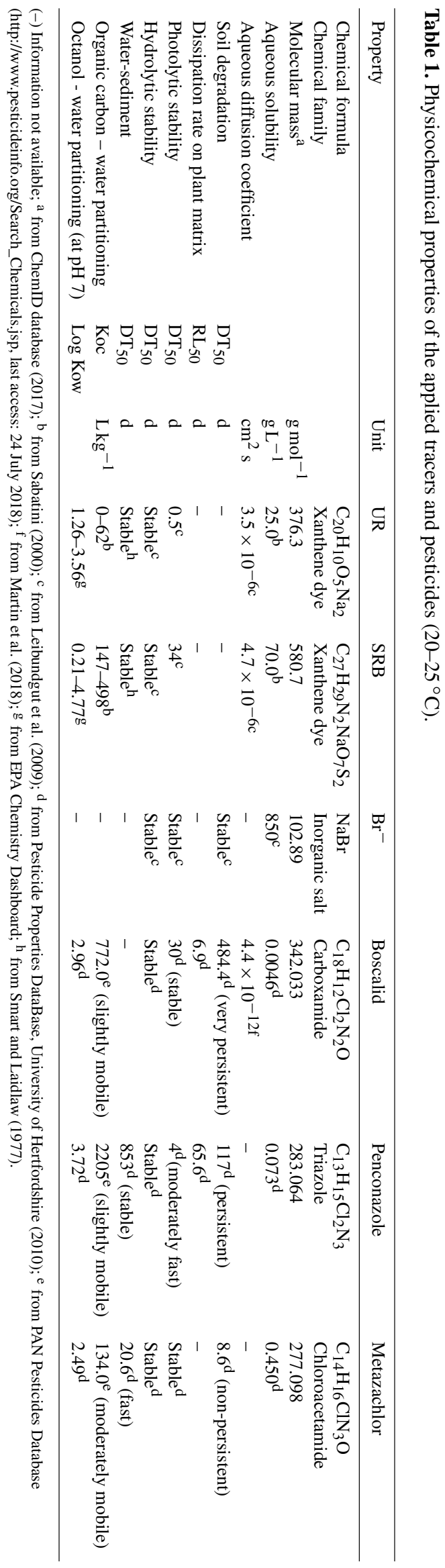

height of $79.8 \pm 18.6$ and $76.9 \pm 10.1 \mathrm{~cm}$, respectively. They were purchased from a local garden center. The whole experiment was carried out indoors in a laboratory assembly; therefore, 64 OSRAM SSL 3W light-emitting diode lamps for plant growth (Purple Alien 2.0, LED Grow Shop, Germany) with daily photoperiods of $11 \mathrm{~h}$ were installed.

The inlet and outlet were intended to create vertical water flows. This was achieved through the installation of two pairs of peristaltic pumps coupled to Plexiglas pipes $(15 \mathrm{~mm}$ diameter) that were connected to the bottom of the system, and another two pairs of peristaltic pumps coupled to Plexiglas pipes that channeled directly into the inlet and outlet reservoirs. A tank with a capacity of $350 \mathrm{~L}$, which was connected to the tap water, served as external inlet reservoir, while a second tank with a capacity of $1000 \mathrm{~L}$ received the waste water. In order to monitor the water level, three pairs of PVC observation pipes (DN: 35-40 mm, STÜWA Konrad Stükerjürgen $\mathrm{GmbH}$, Germany) with a length of $50 \mathrm{~cm}$ were arranged symmetrically on both sides at the center line of the system. Half of the pipes were located in the gravel layer and the other half in the sand.

In order to obtain pore water samples with high vertical resolution, a multilevel pipe with a sampling resolution of $12 \mathrm{~cm}$ was designed. This resulted in a total of four sampling depths that ranged from the gravel to the uppermost layer of the sand. Two multilevel pipes were installed in the sediment bed: one in the non-vegetated half of the system and the other in the vegetated half. Small glass filters $(12.5 \mathrm{~mm}$ diameter, porosity 2 , ROBU, Germany) were installed in both multilevel pipes at each sampling depth. The filters were connected to a multichannel peristaltic pump (pulsefree flow peristaltic pump, Gilson, France) via capillaries made of stainless steel (1/16" inner diameter, Swagelok, Germany) that were directly inserted into TYGON tubes (i.d. $1.02 \mathrm{~mm}$, PRO LIQUID, Germany). In addition, 5TE sensors (Decagon Em50 series, Campbell Scientific) and redox probes (Paleo terra, Amsterdam, the Netherlands) were installed at the same depths in both multilevel pipes. Glass filters, sensors and probes were separated from each other at an angle of $90^{\circ}$ at each sampling depth (Fig. 1b). Furthermore, a reference electrode $(\mathrm{Ag}: \mathrm{AgCl})$ connected to the redox probes was inserted in the sediment between the multilevel pipes. All sensors and probes were connected to a data logger (CR1000, Campbell Scientific).

\subsection{Operation of the model constructed wetland system}

The model constructed wetland system was designed to alternate saturated and unsaturated conditions (long periods of aeration). A total of three phases were created (Fig. 2): (1) saturation with target substances (1 week), (2) drying by evapotranspiration (3 weeks) and (3) saturation with tap water (1 month). During the first saturation phase, only one injection was made, whereas in the second saturation phase, the system was kept saturated by constant injections of tap water. 
Table 2. (a) characteristics and (b) operation of the model constructed wetland system.

\begin{tabular}{|c|c|c|c|c|}
\hline \multicolumn{5}{|l|}{ (a) } \\
\hline Compartment & Parameter & Unit & Sub-compartment & Value \\
\hline \multirow[t]{20}{*}{ Sediments } & Texture $^{\mathrm{a}}$ & $\%$ sand/silt/clay & Sand & $97.8 / 2.3 / 0.1$ \\
\hline & Mean initial organic carbon content ${ }^{\mathrm{a}}$ & $\%$ & Sand & $0.2 \pm 0.02$ \\
\hline & Mean final organic carbon content ${ }^{b}$ & $\%$ & Sand & $0.8 \pm 1.4$ \\
\hline & Mean initial dithionite-extractable Fe $(\mathrm{Fed})^{\mathrm{a}}$ & $\mathrm{g} \mathrm{kg}^{-1}$ & Sand & $1.0 \pm 0.01$ \\
\hline & Mean final dithionite-extractable $\mathrm{Fe}(\mathrm{Fed})^{\mathrm{b}}$ & $\mathrm{g} \mathrm{kg}^{-1}$ & Sand & $1.1 \pm 0.2$ \\
\hline & $\mathrm{pH}\left(\mathrm{H}_{2} \mathrm{O}\right)$ & - & Sand & 9.1 \\
\hline & $\mathrm{pH}\left(\mathrm{CaCl}_{2}\right)$ & - & Sand & 8.1 \\
\hline & Diameter ${ }^{\mathrm{a}}$ & $\mathrm{mm}$ & Sand & $0-2$ \\
\hline & & & Gravel & $4-8$ \\
\hline & Bulk density ${ }^{\mathrm{a}}$ & $\mathrm{kg} \mathrm{L}^{-1}$ & Sand & 1.5 \\
\hline & & & Gravel & 1.6 \\
\hline & Porosity & $\%$ & Sand & 42 \\
\hline & & & Gravel & 45 \\
\hline & Height & $\mathrm{cm}$ & Sand & 32 \\
\hline & & & Gravel & 10 \\
\hline & Surface area & $\mathrm{m}^{2}$ & - & 0.7 \\
\hline & Mass & $\mathrm{kg}$ & Sand & 430.8 \\
\hline & & & Gravel & 124.0 \\
\hline & Redox potential ${ }^{\mathrm{c}}$ & $\mathrm{mV}$ & Sand and gravel & $-328 \pm 10.7$ to $+740 \pm 25.6$ \\
\hline & Conductivity ${ }^{\mathrm{c}}$ & $\mathrm{dS} \mathrm{m} \mathrm{m}^{-1}$ & Sand and gravel & 0 to $0.4 \pm 0.1$ \\
\hline \multirow[t]{6}{*}{ Plants } & Density & No. & Typha latifolia & 4 \\
\hline & & & Phragmites australis & 7 \\
\hline & & Plants $\mathrm{m}^{-2}$ & Typha latifolia & 10.8 \\
\hline & & & Phragmites australis & 18.9 \\
\hline & Mean initial height & $\mathrm{cm}$ & Typha latifolia & $79.8 \pm 18.6$ \\
\hline & & & Phragmites australis & $76.9 \pm 10.1$ \\
\hline \multicolumn{5}{|l|}{ (b) } \\
\hline \multicolumn{3}{|l|}{ Parameter } & Unit & Value \\
\hline \multicolumn{3}{|c|}{ Inlet/outlet pumping rate } & $\mathrm{Lh}^{-1}$ & 21.6 \\
\hline \multicolumn{3}{|c|}{ Peristaltic pumping rate } & $\mathrm{Lh}^{-1}$ & 0.1 \\
\hline \multicolumn{3}{|c|}{ Volume of tracers and pesticides injected } & $\mathrm{L}$ & 40 \\
\hline \multicolumn{3}{|c|}{ Volume of clean water injected at the end of the drying phase } & $\mathrm{L}$ & $34.1 \pm 3.1$ \\
\hline \multicolumn{3}{|c|}{ Volume of total clean water injected in the flushings } & $\mathrm{L}$ & $355.1 \pm 20.5$ \\
\hline \multicolumn{3}{|c|}{ Hydraulic retention time } & $\mathrm{d}$ & $62.5 \pm 2.12$ \\
\hline
\end{tabular}

${ }^{a}$ Determined prior to planting; ${ }^{b}$ determined at the end of the experiment as the mean of all the values measured at the different depths; ${ }^{\mathrm{c}}$ range of values (min to max) measured in the sediment during the experiment. Values represent means \pm standard deviation.

The operation of the constructed wetland is summarized in Table $2 \mathrm{~b}$. The solution of tracers and pesticides was prepared immediately before the injection. To check possible interactions between substances, concentrations in the solution were measured on the day of the injection and a couple of days after. Prior to the injection, the system was drained until field capacity was reached. The whole experiment lasted 7 months (from March 2017 to October 2017), during which two identical experimental runs were performed. The first run (from 9 March to 9 May 2017) was followed by a resting period of about 3 months (from 9 May to 1 August 2017), during which occasional water additions to maintain the vegetation were carried out. After this, the second run (from 1 August to 3 October 2017) was conducted.
The execution of the injections is shown in Fig. 3. Three injections took place in each run of the experiment: (i) initial surface injection of tracers and pesticides, (ii) injection of tap water from the bottom of the system and (iii) flushing of the sediments with tap water from the bottom. The surface injection (i) was performed after the system had been drained. The solution was constantly pumped into the inlet reservoir; it then overflowed the reservoir and entered the sediments bed. Due to the low flow rate the solution first moved downward near the inlet and then upward as the system was filling up. The inflow was held constant for about $2 \mathrm{~h}$ until the system became saturated and the upward flow formed a surface ponding of approximately $2 \mathrm{~cm}$. In this way, possible entrapment of air in the system was avoided. The second in- 


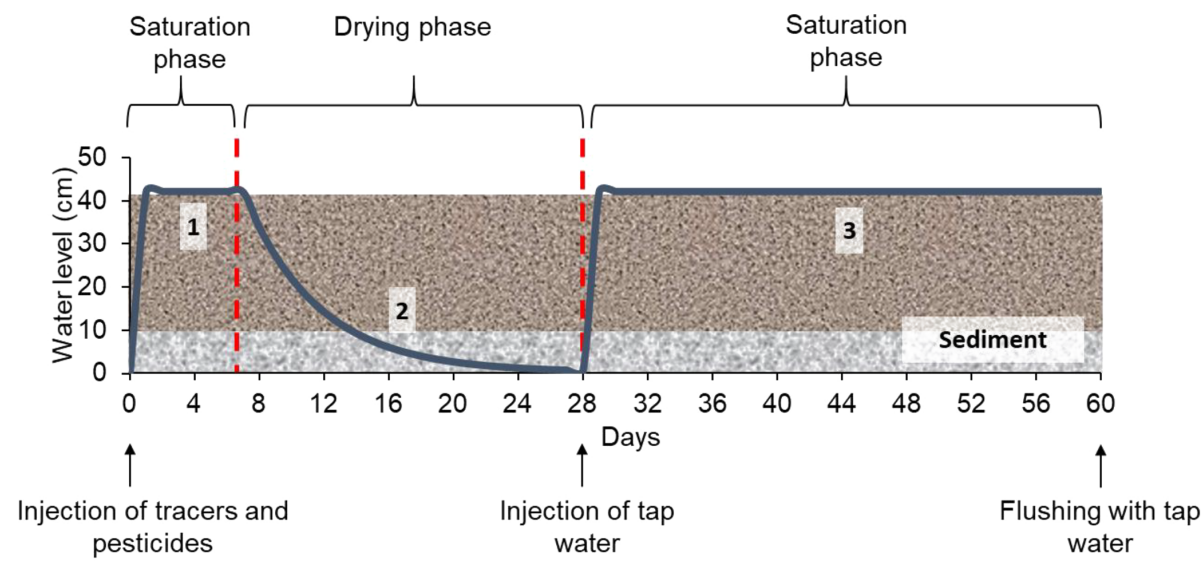

Figure 2. Experimental protocol with the different phases and injections performed during the experiment. The $x$ axis indicates the duration of the experiment, and the $y$ axis indicates the variation of the water level during the different phases. The water level curve (blue) is only schematic and does not correspond to real water level measurements.

jection (ii) was performed at the end of the drying phase by pumping tap water from the bottom of the system. The water flowed evenly through the sediment in an upward direction. Again, the inflow was maintained until the system became saturated and a surface ponding of approximately $2 \mathrm{~cm}$ was formed. This injection was repeated throughout the second saturation phase in order to keep the system constantly saturated. The flushing of the system (iii) was performed at the end of the second saturation phase and was intended to recover all mobile fractions of the target compounds. To do this, tap water was injected from the bottom and was allowed to flow into the system continuously. Water overflowed the main bed and exited towards the outlet reservoir, from where it was pumped to the waste tank.

\subsection{Sampling and monitoring}

Pore water samples were collected from different depths twice a week during the experimental runs. The sampling of pore water was performed simultaneously in order to prevent the mixing of waters. A volume of $60 \mathrm{~mL}$ of pore water was transferred to $100 \mathrm{~mL}$ brown glass bottles and stored at $4{ }^{\circ} \mathrm{C}$ for the analysis of major ions and tracers. Previously, a volume of $10 \mathrm{~mL}$ was transferred to $15 \mathrm{~mL}$ polypropylene tubes and stored at $-20^{\circ} \mathrm{C}$ for the subsequent pesticide and TPs analysis. Polypropylene was chosen instead of glass because the samples had to be frozen immediately after their collection. Such material has already been used to store pesticides in other studies (e.g., Joseph, 2015). Additional pore water samples were taken before and after the initial injections of tracers and pesticides to account for the background. During the flushing of the system, surface water samples were collected at the outlet and transferred to $100 \mathrm{~mL}$ brown glass bottles. Following this, the samples were stored at $4{ }^{\circ} \mathrm{C}$ for the subsequent analysis of major ions and tracers, and at $-20^{\circ} \mathrm{C}$ for the analysis of pesticides and TPs.
At the end of the experiment the sediment bed was emptied of its gravitational water. Then, 16 sediment cores (four per longitudinal and four per lateral transect) were collected by inserting plastic pipes into the sediment. Sediment cores were divided into four fractions, each representing a different sampling depth $(0-8,9-20,21-32$ and $33-42 \mathrm{~cm})$. The sediment samples were dried at room temperature for $24 \mathrm{~h}$ and stored in the dark for subsequent measurement of tracers, total organic carbon and iron oxides. Following this, the plants were removed from the vegetated zone and separated into aerial parts (stems and leaves) and roots. Immediately after, they were oven dried at $60^{\circ} \mathrm{C}$ for approximately $24 \mathrm{~h}$ and stored in the dark for subsequent measurement of tracers. Biomass was determined on a dry matter basis.

Temperature, soil moisture, conductivity and redox potential were constantly monitored by means of the data logger with an interval of 2 min throughout the entire experiment. Redox potential was calculated by adding the potential from the reference electrode $(\mathrm{Ag} / \mathrm{AgCl})$ to the measured potential (Vorenhout et al., 2011). The final result was corrected for differences in temperature according to Bard et al. (1985).

\subsection{Laboratory analysis}

\subsubsection{Major ions and tracers in the pore water and outlet water}

Pore water and outlet water samples were measured for major ions $\left(\mathrm{Na}^{+}, \mathrm{NH}_{4}^{+}, \mathrm{K}^{+}, \mathrm{Ca}^{2+}, \mathrm{Mg}^{2+}, \mathrm{Br}^{-}, \mathrm{SO}_{4}^{2-}, \mathrm{Cl}^{-}\right.$, $\mathrm{NO}_{3}^{-}$and $\mathrm{NO}_{2}^{-}$) by ion chromatography (Dionex ICS-1100, Thermo Scientific, USA). All samples had previously been filtered with a $0.45 \mu \mathrm{m}$ filter.

Concentrations of UR and SRB in pore and outlet water samples were measured by fluorescence spectrometry (Perkin Elmer LS-50B) as previously described (Leibundgut et al., 2009). Briefly, a synchronous scan method was applied 


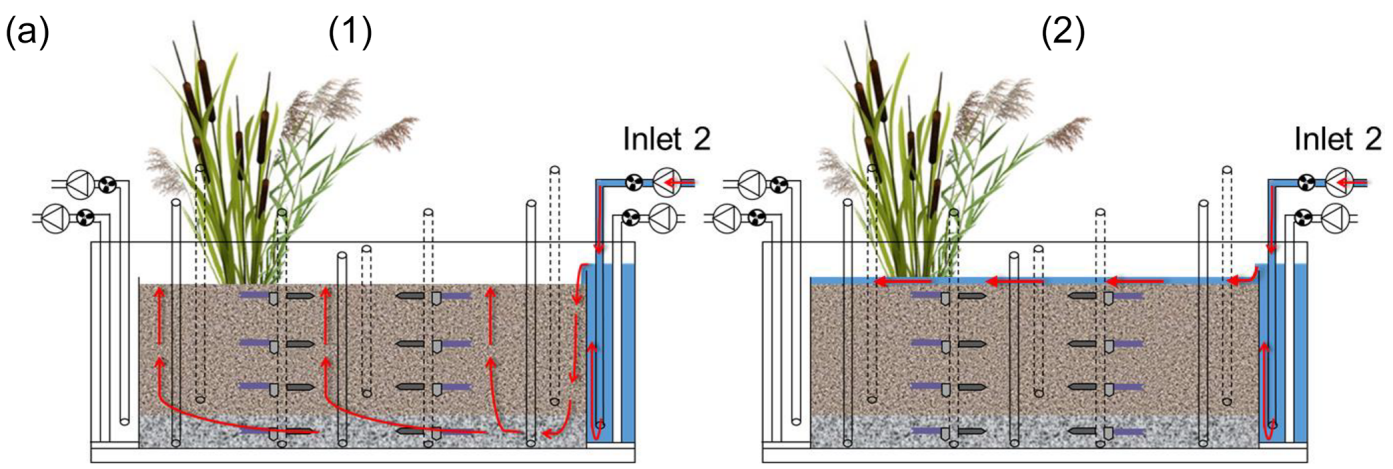

(b)

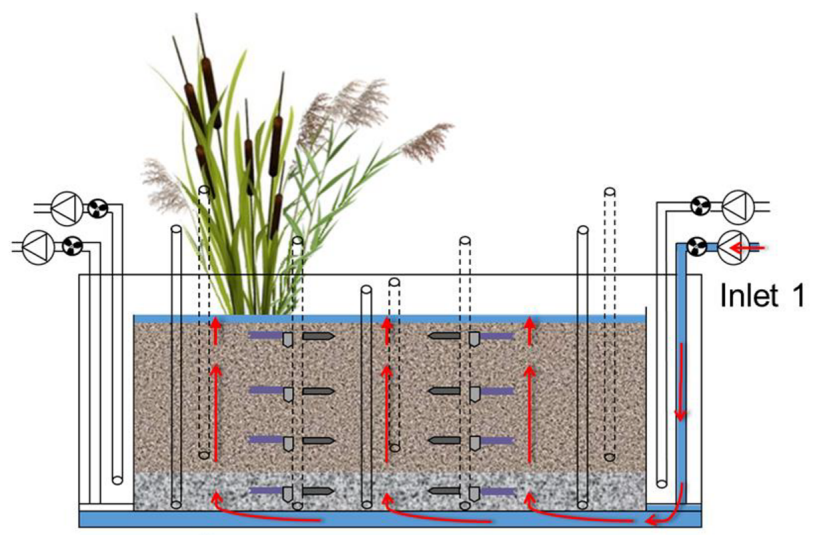

(c)

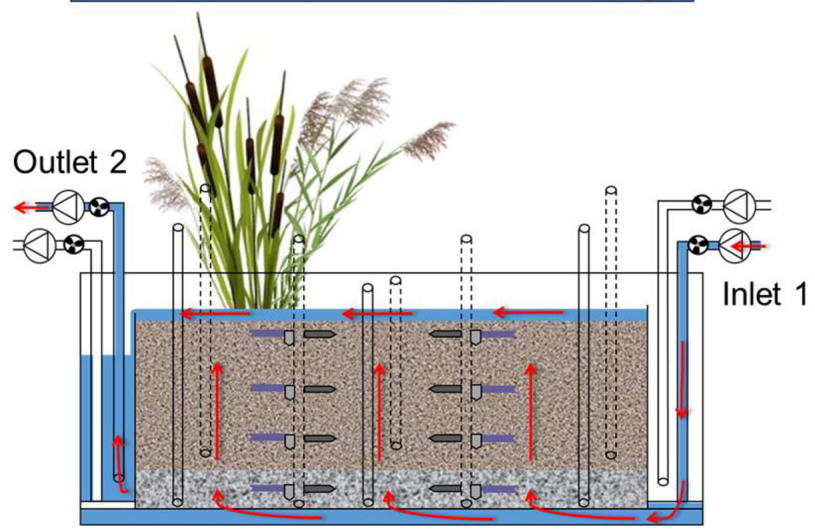

Figure 3. Front view of the model constructed wetland system showing the execution of the injections (red arrows indicate the direction of the water flow): (a) surface injection of tracers and pesticides, (1) corresponds to the upward vertical filling and (2) to the flow on the surface while the ponding was forming, (b) injection of tap water from the bottom and (c) flushing of the system with tap water from the bottom.

with an excitation/emission wavelength difference of $25 \mathrm{~nm}$ and target wavelengths of 488 and $561 \mathrm{~nm}$ for UR and SRB, respectively. Detection limits were $0.05 \mu \mathrm{g} \mathrm{L}{ }^{-1}$ for UR and $0.1 \mu \mathrm{g} \mathrm{L}^{-1}$ for SRB. The entire fluorescent spectrum (from 350 to $600 \mathrm{~nm}$ ) was analyzed in order to identify different background fluorescent levels and subtract them.

\subsubsection{Pesticides and TPs in the pore water and outlet water}

Pore water and outlet water samples were analyzed for the pesticides boscalid, penconazole, metazachlor and their known TPs - met-ESA and met-OA (metazachlor), $p$ chlorobenzoic acid (boscalid), and 1,2,4-triazole (penconazole). Acetonitrile (LC-MS grade; VWR International GmbH, Darmstadt, Germany) was used as the organic mobile phase in chromatography and for the preparation of stock solutions. The aqueous mobile phase was prepared with ultrapure water (MembraPure $\mathrm{GmbH}$, Germany; Q1: $16.6 \mathrm{M} \Omega$ and Q2: 18.2 M $\Omega$ ). Samples were filtered using syringe filter units (CHROMAFIL $^{\circledR}$ Xtra RC20/25; Macharey-Nagel, GmbH \& Co. KG, Germany). Each sample $(990 \mu \mathrm{L})$ was spiked with $10 \mu \mathrm{L}$ terbutryn- $\mathrm{d}_{5}$ as in- 
ternal standard. Analysis of $5 \mu \mathrm{L}$ of each sample was carried out by LC-MS-MS (Agilent Technologies, 1200 Infinity LCSystem and 6430 Triple Quad, Waldbronn, Germany). Mobile phases were $0.01 \%$ formic acid (A) and acetonitrile (B) with a flow of $0.4 \mathrm{~mL} \mathrm{~min}^{-1}$. The gradient was as follows: 0 $1 \mathrm{~min}(10 \% \mathrm{~B}), 1-11 \mathrm{~min}(10 \%-50 \% \mathrm{~B}), 11-18 \mathrm{~min}(50 \%-$ $85 \%$ B), 18-21 min (85\%-90\% B), 21-24 min (90\% B), $24-26 \mathrm{~min}(90 \%-10 \% \mathrm{~B})$ and $26-30 \mathrm{~min}(10 \% \mathrm{~B})$. A NUCLEODUR ${ }^{\circledR}$ RP-C18 (125/2; 100-3 $\mu$ m C18 ec) column (Macherey Nagel, Düren, Germany) was used as the stationary phase, and the oven temperature was set to $30^{\circ} \mathrm{C}$. The limits of detection (LOD) and quantitation (LOQ) were calculated with DINTEST Version 2003 (Schmitt and Herbold, 2003) according to DIN 32645. LOQ/LOD values for pesticides and transformation products are provided in Table S2 in the Supplement.

\subsubsection{Extraction and measurement of tracers in the sediments and plants}

UR and SRB in the sediment (sand) and plants were extracted as described by Wernli (2009). In brief, $2 \mathrm{~g}$ of the dried material were mixed with $10 \mathrm{~mL}$ of ammonia-ethanol solution $(40: 60, v / v)$. Dried stems, leaves and roots had previously been ground with a vibratory disc mill (SIEBTECHNIK GmbH, Germany). All samples were shaken on an IKA HS 250 reciprocating shaker for $30 \mathrm{~min}$ at $240 \mathrm{rpm}$ and stored at $4{ }^{\circ} \mathrm{C}$ in the refrigerator for at least $24 \mathrm{~h}$. Afterwards, supernatant was collected, filtered $(<0.45 \mu \mathrm{m})$ and measured for the tracers. The resulting curves were corrected via interpolation and subtraction of the background signal from the peak intensity as described by Leibundgut et al. (2009).

A different methodology based on McMahon et al. (2003) was used to measure $\mathrm{Br}^{-}$in the sediment (sand) and plants to avoid the interference from the ammonia-ethanol solution with the ion chromatograph. Samples were prepared in the same way as previously described, but they were mixed with $20 \mathrm{~mL}$ of deionized water instead. Following this, they were shaken on an IKA HS 250 reciprocating shaker for $1 \mathrm{~h}$ at $240 \mathrm{rpm}$ and later centrifuged at $3000 \mathrm{rpm}$ for $30 \mathrm{~min}$ (Megafuge 1.0R; Heraeus Instruments). Supernatant was then taken, filtered $(<0.45 \mu \mathrm{m})$ and measured by ion chromatography (Dionex ICS-1100, Thermo Scientific, USA).

\subsubsection{TOC and iron oxides in the sediment}

Total organic carbon (TOC) in the sediment (sand) was measured with a CNS analyzer (Vario El Cube, Elementar, Germany) after grinding the dried samples with a vibratory disc mill (Siebtechnik GmbH, Germany). Dithioniteextractable $\mathrm{Fe}\left(\mathrm{Fe}_{\mathrm{d}}\right)$ in the sediment (sand) was extracted according to Mehra and Jackson (1960) and measured using inductively coupled plasma-optical emission spectrometry
(Spectro Ciros CCD, Spectro Analytical Instruments GmbH, Germany).

\subsection{Data analysis}

Spatial and temporal dynamics of transport processes in the pore water were investigated by analyzing soil moisture data and $\mathrm{Br}^{-}$breakthrough curves. Here, $\mathrm{Br}^{-}$was chosen as reference due to its conservative character. The occurrence and role of retardation was studied by performing crosscorrelations between $\mathrm{Br}^{-}$time series. The predominance of transport processes among the solutes was examined by looking at the relationship between $\mathrm{Br}^{-}$and the other solutes via correlation matrices of the measured concentration time series. It was assumed that a weak correlation would be due to the prevalence of sorption and transformation rather than transport. This was based on the premise that the solutes would experience retardation due to sorption or attenuation due to transformation. Transformation processes were examined via the detection of TPs. The calculated correlation matrices were also used to analyze the general behavior of the solutes and their relationship in the pore water. Spearman rank correlation coefficients $\left(\rho_{\mathrm{s}}\right)$ were applied as the data did not fit a normal distribution. Correlations were calculated individually for the vegetated and non-vegetated zones and the different depths. The influence of vegetation and hydrologic conditions on transport and dissipation processes was evaluated through the comparison of the results of the vegetated with the non-vegetated zone and the different phases. In addition, the performance of the two experimental runs was assessed using correlations between $\mathrm{Br}^{-}$breakthrough curves from the first and second runs.

Further comparisons between tracers, pesticides and their TPs were made by analyzing their cumulative recovery curves obtained at the outlet after the flushing phase. The fate of the tracers and main dissipation pathways were examined with a final overall mass balance that accounted for five different compartments (pore water, outlet water, sediments, stems and leaves, and roots). The mass of tracers and pesticides recovered in the pore water was calculated as the sum of the weekly dissolved concentrations multiplied by the volume sampled. The mass of tracers and pesticides recovered in the outlet water was calculated based on the recovery curves obtained during the flushing phase. The mass of tracers and pesticides recovered in the sediments and plants was determined as the concentrations measured in their corresponding compartments multiplied by the total amount of sediments and plants in the system, respectively.

In the present study pesticides and their TPs could not be measured in the sediment and plants because a quantitative method was lacking. This issue pointed to the advantage of using tracers instead of pesticides as the former are generally easier to measure. Statements about the behavior of pesticides in the compartments where they could not be measured, were made according to their physicochemical prop- 
erties, the results of the breakthrough and recovery curves, and their comparison with the tracers.

\section{Results and discussion}

\subsection{Transport processes in the pore water according to $\mathrm{Br}^{-}$behavior}

The relative concentrations of $\mathrm{Br}^{-}$measured at different depths (Table S3) indicated that similar values were reached in the lower- and uppermost layers right after the injection. In contrast, no $\mathrm{Br}^{-}$was detected in the middle sections. These results were attributed to the conditions previous to the injection (i.e., system at field capacity). In such context, the presence of water-filled pores may have caused heterogeneities resulting in an uneven distribution of solutes within the system. Indeed, soil moisture values (Fig. S2) measured prior to the injections (indicated with a red circle) were 2-3 times higher in the middle sandy layers $(15$ and $27 \mathrm{~cm})$ compared with the lower- and uppermost layers $(39$ and $3 \mathrm{~cm}$, respectively). Moreover, such values barely changed over the experiment, suggesting that the water holding capacity of the middle sections was higher than the other layers (at least in the vegetated zone, as there are no data from the non-vegetated). These results were associated with a possible lack of connectivity, as already suggested by Nimmo (2012). Consequently, water flow through these sections was most likely inhibited and/or delayed, as evidenced by the initial absence of $\mathrm{Br}^{-}$(Table S3) and the subsequent delay of the breakthrough peaks (see Fig. 4).

Conversely, given that $\mathrm{Br}^{-}$was detected in the uppermost layer (see Table S3), it was assumed that the heterogeneities due to the presence of poorly connected pores in the middle layers were only located in some areas, including the surroundings of the sampling ports. In the rest of the system matrix flow probably dominated. According to Fig. 4, the uppermost layer displayed a delayed breakthrough peak with relative concentrations of $\mathrm{Br}^{-}$about 3 times higher than the maximum detected at the bottom (see also Table S3). In addition, the maximum values reached in the vegetated zone of the uppermost layer were twice as high as those of the non-vegetated zone, although these differences were not that pronounced in the second run. Hence, it can be speculated that lateral transport at or near the surface may have occurred during the injections causing augmented transport of solutes towards the vegetated surface. However, other possible explanations could not be ruled out. These include the likely influence of the plants by means of water uptake and the possible contribution of the roots to the formation of channels through which preferential flow took place. Other mechanisms, not necessarily related to plants (e.g., fingering), may have also been involved in the transport of solutes to the vegetated area.
Lag correlations performed using the $\mathrm{Br}^{-}$breakthrough curves (Fig. 5) confirmed the delayed arrival of solutes to the middle and uppermost layers. A significant lag correlation could only be observed in the non-vegetated zone. Specifically, the delays obtained in the middle layers (at time $t=-7$ and $t=-3$ in the first and the second runs, respectively) were greater than those obtained in the uppermost layer (at time $t=-5$ and $t=-2$ in the first and the second runs, respectively). The delayed peak of $\mathrm{Br}^{-}$observed at a depth of $15 \mathrm{~cm}$ in the non-vegetated area for the first run was also detected by the conductivity probe located at the same depth. The complete breakthrough curve could not be captured by the sensor, but a strong correlation (Spearman's $\rho=0.83$ and $p$ value $<0.001$ ) between $\mathrm{Br}^{-}$and the conductivity values was found (see Table S4). Similar results were not observed in the non-vegetated layer at a depth of $27 \mathrm{~cm}$ due to the failure of the sensor. Overall, the delayed peak of solutes in the middle layers coincided in time with the end of the drying phase and the beginning of the second saturation phase. Hence, it was related to the likely migration of solutes during the drop and subsequent rise of the water table. In contrast, the delayed peak of the uppermost layer was associated with possible low pore connectivity in the vicinity of the sampling ports. Here the solutes probably arrived earlier, but we could not measure them at the time of the arrival presumably because of the presence of water-filled pores in the surroundings of the sampling ports.

If we compare the performance of the vegetated and nonvegetated zones by means of correlations (Table S5), we observe stronger correlations in the lower layers (depths of 27 and $39 \mathrm{~cm}$ ) than in the upper layers (depths of 15 and $3 \mathrm{~cm}$ ), especially in the uppermost layer during the first run. These results suggested a greater influence from vegetation and/or other causes (e.g., transport along the surface) on solute transport in the upper layers. These findings also indicated that the system did not behave the same way in each run. In fact, if we evaluate the performance of the system over time, differences were observed (Table 3 ). With the exception of the uppermost layer, the non-vegetated zone of the other layers showed a strong correlation between the two runs, whereas in the vegetated zone some layers did not show any correlation (layer at a depth of $27 \mathrm{~cm}$ ) or displayed correlations that were statistically non-significant (layers at depths of 15 and $39 \mathrm{~cm}$ ). These results indicated that the overall performance of the non-vegetated zone was similar in both runs, whereas the vegetated zone behaved differently. This was not applicable to the uppermost layer because it was probably influenced by the presence of plants and/or transport along the surface. Lag correlations between the first and second runs were also analyzed (Fig. S3). A significant value (at time $t=-3$ ) was found in the vegetated zone at a depth of $15 \mathrm{~cm}$. In general, these results were related to possible changes in root density and/or spatial distribution in the system over time. This assumption was supported by visual observations of the sediment (Fig. 6). However, other causes, such as the 
(a)
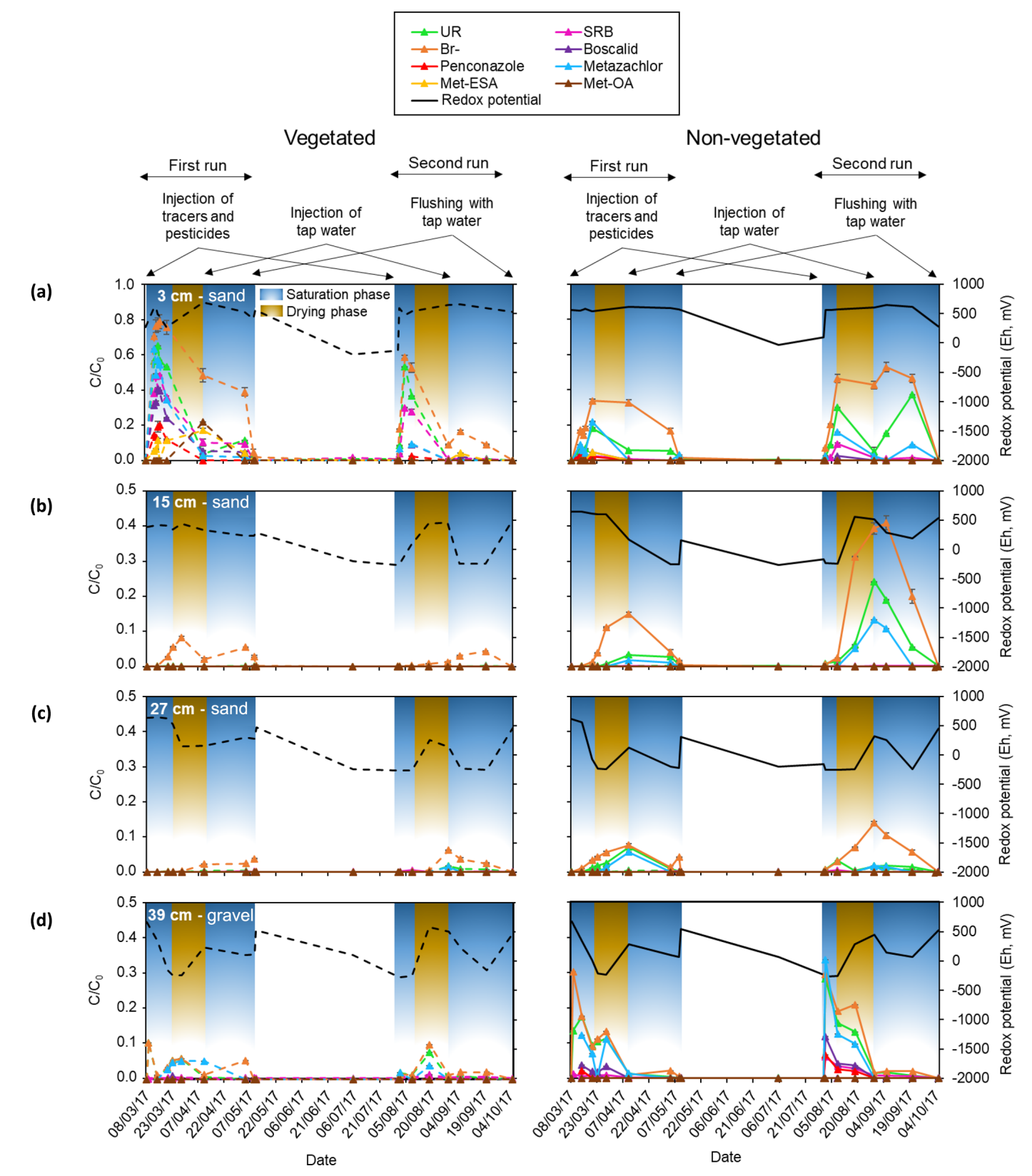

Figure 4. Breakthrough curves of the different tracers, pesticides and their TPs in terms of relative concentrations $\left(C / C_{0}\right.$; obtained by scaling with the input concentrations) measured in the pore water during the first and second run for the different zones, phases (saturation and drying) and the following depths: (a) $3 \mathrm{~cm}$, (b) $15 \mathrm{~cm}$, (c) $27 \mathrm{~cm}$ and (d) $39 \mathrm{~cm}$. Changes in redox potential are displayed on the right $y$ axis $(\mathrm{Eh}$ in $\mathrm{mV})$. The different injections performed during each run are displayed on top of the figure. Note that the scale of the relative concentrations corresponding to the sampling depth of $3 \mathrm{~cm}$ is extended.

influence of flushing between runs and $\mathrm{Br}^{-}$uptake by the plants (Xu et al., 2004) could not be ruled out.

\subsection{Relationship between solutes and their behavior in the pore water throughout the experiment}

Overall, the injected solutes followed the same trend as $\mathrm{Br}^{-}$ in the lower- and uppermost layers (Fig. 4). In the middle sections, only UR and metazachlor behaved similarly to $\mathrm{Br}^{-}$, although this was exclusively observed in the non-vegetated part. In fact, the vegetated zone only displayed observable amounts of $\mathrm{Br}^{-}$. Here in the middle layers, dominant processes most likely differed between zones, as was also evidenced by the different redox potentials measured in the vegetated and non-vegetated zone (see Fig. 4, right $y$ axis).

Two of the major metabolites of metazachlor, namely metESA and met-OA, were measured in the uppermost layer. It 
(a)
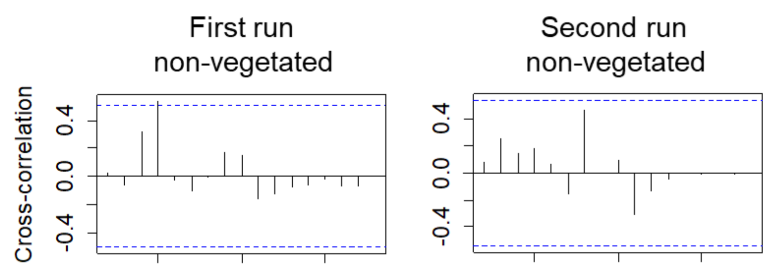

(b)

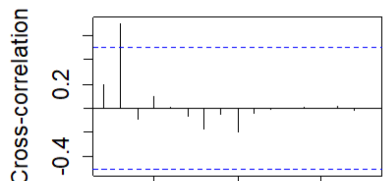

(c)
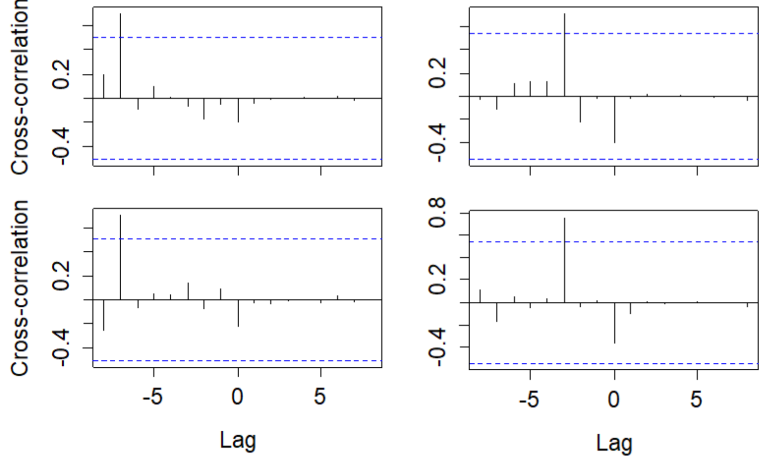

Figure 5. Lag analysis performed using the $\mathrm{Br}^{-}$breakthrough curves for the first and second runs between the following sampling depths: (a) 39 and $3 \mathrm{~cm}$, (b) 39 and $15 \mathrm{~cm}$ and (c) 39 and $27 \mathrm{~cm}$. Only significant lag correlations are displayed. Lag units are given in days (corresponding to the dates when the observations were made). The blue lines represent the approximate $95 \%$ confidence intervals.

Table 3. Spearman rank correlation between the breakthrough curves of $\mathrm{Br}^{-}$of the first and second runs and the different depths and zones.

\begin{tabular}{llcl}
\hline Depth $(\mathrm{cm})$ & Zones & rho & $p$ value \\
\hline \multirow{2}{*}{3} & Non-vegetated & 0.29 & 0.56 \\
& Vegetated & 0.14 & 0.80 \\
\hline \multirow{2}{*}{15} & Non-vegetated & 0.84 & $<0.01^{* *}$ \\
& Vegetated & 0.55 & 0.17 \\
\hline \multirow{2}{*}{27} & Non-vegetated & 0.77 & $0.03^{*}$ \\
& Vegetated & 0.26 & 0.53 \\
\hline \multirow{2}{*}{39} & Non-vegetated & 0.73 & $0.04^{*}$ \\
& Vegetated & 0.55 & 0.15 \\
\hline
\end{tabular}

The significance levels are displayed as follows: $p<0.001 * * *$; $p<0.01^{* *} ; p<0.05^{*}$.

should be noted that other transformation products may have been formed in our system. However, such compounds were most likely below the limit of quantification $(\leq 9.29$ and $\leq 10.28 \mu \mathrm{g} \mathrm{L}^{-1}$ for $p$-chlorobenzoic acid and 1,2,4-triazole, respectively); therefore, they could not be identified. MetESA peaked first (day 6) in the vegetated zone. A total of $5 \mathrm{~d}$ later it appeared in the non-vegetated zone at half of the relative concentration. However, during the same phase of the second run no TPs were found. A second peak of both metESA and met-OA, with about double the previously measured relative concentration, was observed in the vegetated uppermost layer $32 \mathrm{~d}$ after the initial injection during the first run. However, in the same period of the second run only metESA peaked, displaying residual amounts.

According to the correlations performed on the solute time series (Fig. 7), two locations exhibited the strongest relationships: the non-vegetated part of the lowermost layer and the vegetated part of the uppermost layer. These areas coincided with the beginning and end of the transport regime through the system. Boscalid and penconazole did not correlate with $\mathrm{Br}^{-}$in the vegetated part of the lowermost layer and the non-vegetated zone of the uppermost layer. These results pointed out that other processes besides transport (e.g., sorption or plant uptake) probably dominated the dissipation of these compounds during the experiment. In the middle layers only UR and metazachlor exhibited significant correlations with $\mathrm{Br}^{-}$, although metazachlor did not show any correlation in the vegetated zone. These findings suggested that transport was the dominant process for metazachlor in the absence of vegetation, whereas under the influence of plants, it most likely experienced other processes (i.e., plant uptake, mineralization in the roots, sorption and/or transformation). In contrast, UR was correlated with $\mathrm{Br}^{-}$in all layers regardless of the presence of vegetation. Therefore, transport was almost certainly a dominant process for this tracer in the pore water. This was not the case for SRB, which only displayed strong positive correlation with $\mathrm{Br}^{-}$in the lower- and uppermost layers. The former was explained by possible high conductivity and low sorption in the gravel. The results from the uppermost layer were associated with the likely promotion of transport towards the vegetated surface, given the strong sorptive character of SRB. Met-ESA also displayed a strong positive correlation with the tracers and pesticides in the vegetated zone of the uppermost layer. On the contrary, met-OA did not show any statistically significant correlation. However, no conclusion could be drawn for the TPs, given the generally lower amounts detected in the present study.

\subsection{Spatial and temporal dynamics of transport and dissipation processes: the role of vegetation and hydrologic conditions}

Spatial and temporal variability of transport and dissipation processes were associated with the conditions prior to injection, the way the solutes entered the system, the presence of plants and the promotion of aeration during the drying phase. Most of the solutes went to the lower- and uppermost layers. The highest concentrations were recorded in the vegetated part of the uppermost layer soon after the injection. This suggested that transport of solutes was favored towards the vegetated surface, which has already been observed in other studies (Holden, 2005; Durst et al., 2013). Conversely, we speculated that transport was retarded in the middle layers because of the presence of water-filled pores before the injection and low pore connectivity. 

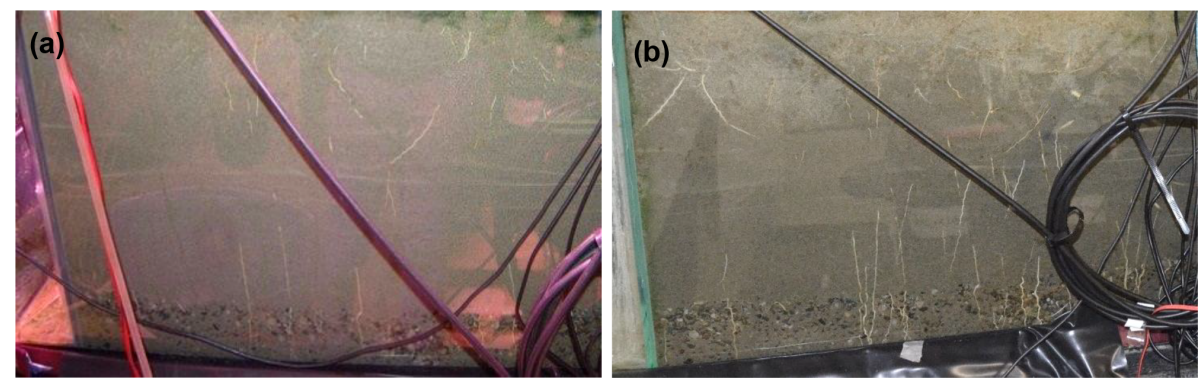

Figure 6. Front view photograph of the root system in the vegetated part of the model constructed wetland: (a) before the first run and (b) at the end of the second run.

Metazachlor TPs were only found in the uppermost layer and their maximum relative concentrations were measured in the vegetated part after the promotion of aerated conditions. It should be noted, however, that the process of transformation may have been a function of time, and transport over that time ended in the vegetated part of the uppermost layer. Hence, the uppermost layer (possibly the vegetated part) and the end of the drying phase may have constituted hot spots and hot moments for transformation processes, respectively. Higher sorption activity was attributed to the same layer as a migration of the most sorptive solutes (SRB, boscalid and penconazole) was not observed. In contrast, the most mobile ones $\left(\mathrm{Br}^{-}, \mathrm{UR}\right.$ and metazachlor) were transported to the nonvegetated part of the middle layers during the drop and subsequent rise of the water table. In the vegetated part of the middle layers only $\mathrm{Br}^{-}$displayed observable amounts (see Fig. 4). This pointed out that besides plant uptake and transformation, retention processes may also have played a major role in the vegetated zone. This hypothesis was in agreement with the amount of SRB found in the sediment (see Fig. S4). It was assumed that sorption velocity was highest at the beginning of the experiment given the rapid decrease in relative concentrations of SRB, boscalid and penconazole. In the later phases, sorption probably decreased due to a decline in the number of free sorption sites.

The results of our study underlined the importance of plants with respect to promoting dissipation processes in constructed wetlands. Indeed, plants have already been attributed the ability to facilitate elimination, degradation and retention of pesticides in wetland systems (Liu et al., 2018). However, our findings also suggested that plant roots may be involved in the formation of preferential flow paths, which could result in a rapid transport of contaminants and a decrease in the interactions between solutes and sediments (Durst et al., 2013). Plant roots have been related to the creation of discontinuities in the soil profile, the greater presence of macropores and the occurrence of bypass flow (Ghestem et al., 2011). Therefore, the beneficial impact of plants in terms of elimination, degradation and retention may be reduced by the occurrence of preferential flows.
Our results also indicated that the promotion of aeration facilitated the degradation of some substances. This was in agreement with recent studies that have demonstrated that intermittent flow regimes support aerobic microbial populations and boost degradation rates of pesticides (e.g., Karpuzcu et al., 2013; Maillard et al., 2016). Other authors have also found that by alternating drainage with non-drainage periods in constructed wetlands, these systems are capable of reducing non-point pollution (Vallée et al., 2015). Hence, the mitigation capacities of constructed wetlands might be improved if aerated conditions are fostered.

\subsection{Recoveries of solutes at the outlet}

The results of the cumulative recovery curves obtained at the outlet are displayed in Fig. 8. During the first flushings, we observed a rapid increase in accumulated mass recovery for $\mathrm{Br}^{-}$, whereas the rest of the solutes displayed comparatively slower increases. In the following flushings, the accumulated mass recovery of SRB, penconazole and boscalid gradually increased, whereas for $\mathrm{Br}^{-}$, UR and metazachlor it stabilized. These results suggested that the retained fractions of SRB, boscalid and penconazole in the soil were greater than for $\mathrm{Br}^{-}$, UR and metazachlor. Indeed, the sorptive character of SRB, boscalid and penconazole has already been reported in the literature (Long et al., 2005; Vallée et al., 2014; Dollinger et al., 2017). In the fourth flushing, SRB, boscalid and penconazole still exhibited increases in their accumulated mass recoveries (Fig. 8a1, b1). However, SRB showed higher mass recovery than boscalid and penconazole (Table 4). These findings were associated with the different physicochemical properties of boscalid and penconazole compared with SRB. According to this, different mechanisms are expected to be involved in their sorption, which will ultimately affect their fate in the environment. SRB has, in addition to a nonpolar region, both charged groups (cationic and anionic). Hence, it is susceptible to sorption onto positively and negatively charged mineral sites, $\mathrm{OH}-$ groups of hydroxides, clay minerals and organic matter (Kasnavia et al., 1999; Polat et al., 2011). This particular characteristic of SRB must be taken into account when using such 


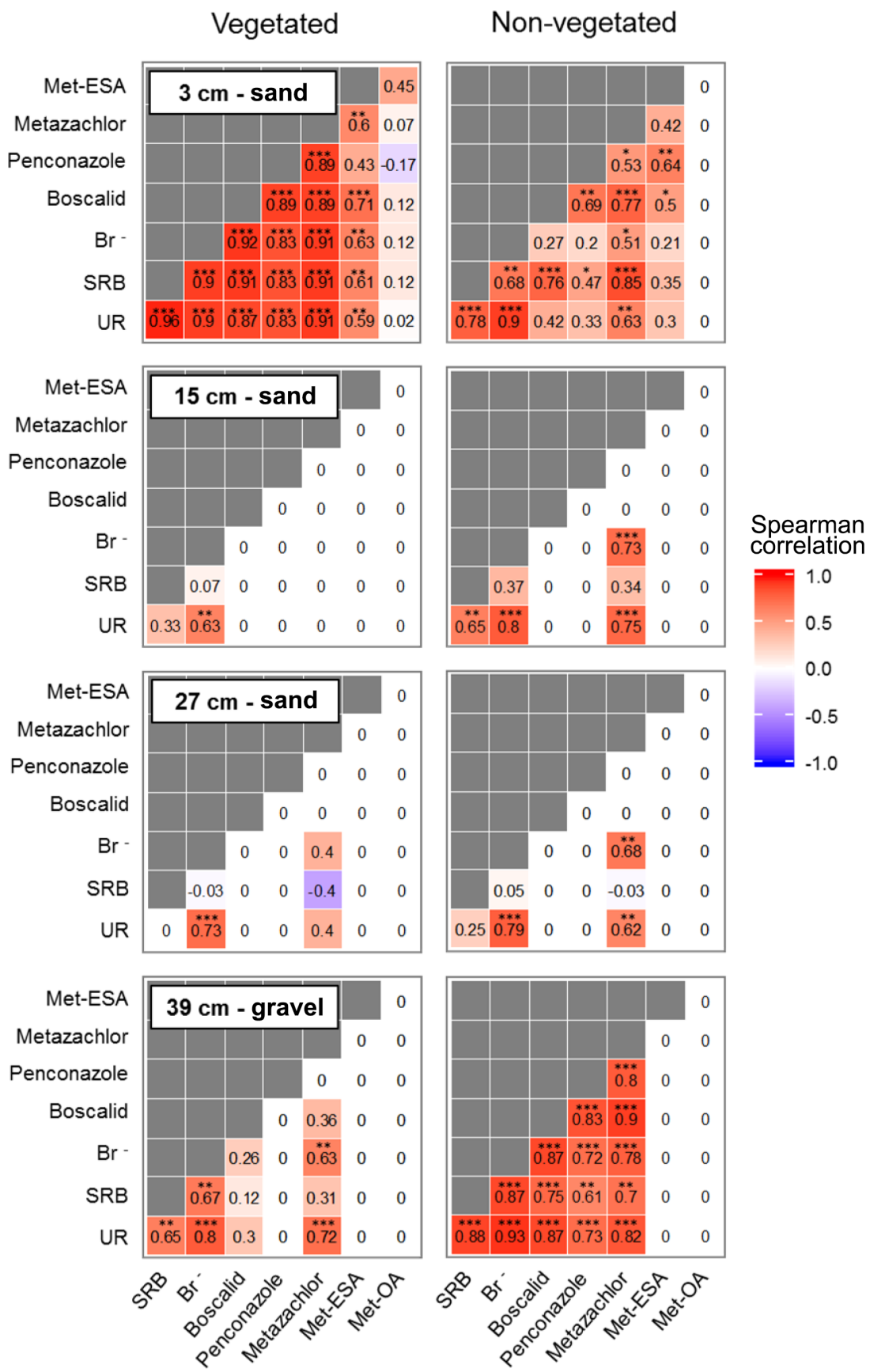

Figure 7. Spearman correlation matrices between the relative concentration of tracers, pesticides and their TPs in the pore water during the whole experiment, distinguishing between the different depths and zones. The significance levels are displayed as follows: $p<0.001 * * *$; $p<0.01^{* *} ; p<0.05^{*}$.

a tracer to investigate sorption processes of pesticides inside wetland systems.

Cumulative recovery curves of metazachlor TPs were also detected at the outlet during the flushings (Fig. 8). Even though small amounts of TPs were obtained, it was an indication that they were not further degraded or retained in the system, which was in agreement with the findings of other studies (Mamy et al., 2005; EFSA, 2008a). Higher amounts of met-ESA were recovered compared with met-OA.

According to the total amount of tracers and pesticides recovered at the outlet after the flushings (Table 4), the solutes were classified as follows (from highest to lowest recovery rate): $\mathrm{Br}^{-} \gg \mathrm{SRB} \gg \mathrm{UR} \gg$ Boscalid $\gg$ Penconazole $\gg$ Metazachlor. Several processes, mostly adsorption by substrates, transformation and plant uptake, were responsible 
(a)

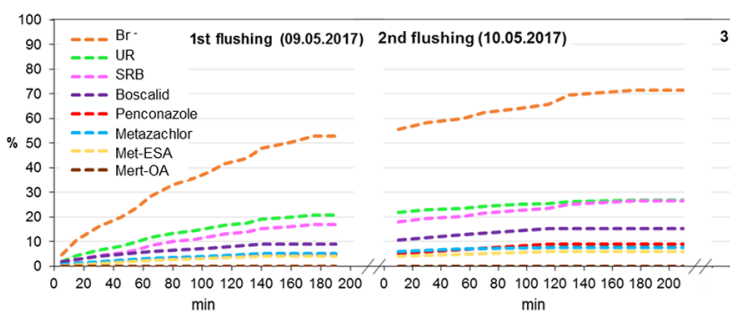

(b)

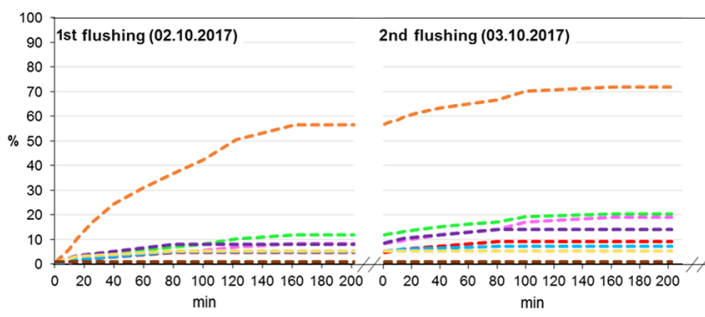

3rd flushing (11 .05.2017)

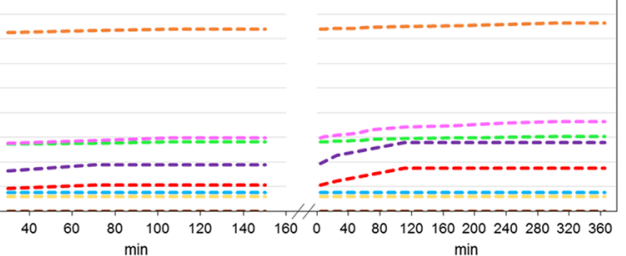

min

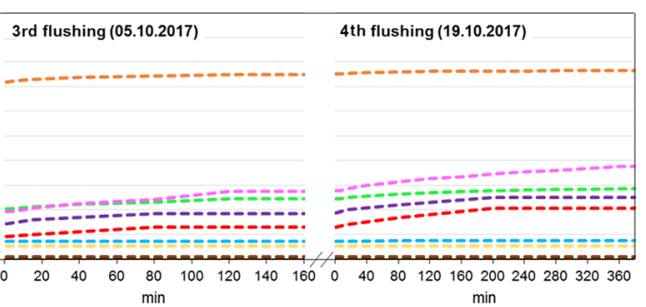

(a1)

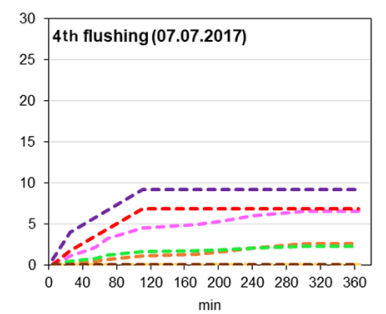

(b1)

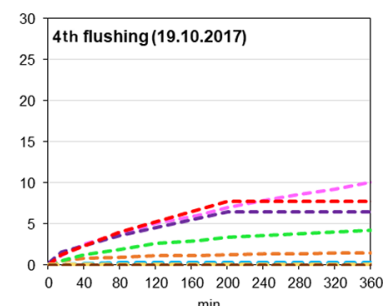

Figure 8. Cumulative recovery curves of tracers, pesticides and their TPs obtained during the flushing phase for the (a) first and (b) second runs. Recovery curves for the fourth flushing are detailed in (a1) and (b1) for the first and second runs, respectively.

Table 4. Percentage of tracers, pesticides and their TPs recovered (and the corresponding removals) from the outlet water after the flushing phase for the first and second runs.

\begin{tabular}{|c|c|c|c|c|c|c|}
\hline & \multicolumn{2}{|c|}{$\begin{array}{c}\text { Recovery water } \\
\text { outlet }(\%)\end{array}$} & \multirow{2}{*}{$\begin{array}{r}\text { Mean } \\
\text { recovery } \\
(\%)\end{array}$} & \multicolumn{2}{|c|}{ Removal (\%) } & \multirow{2}{*}{$\begin{array}{c}\text { Mean } \\
\text { removal } \\
(\%)\end{array}$} \\
\hline & $\begin{array}{c}\text { First } \\
\text { run }\end{array}$ & $\begin{array}{r}\text { Second } \\
\text { run }\end{array}$ & & $\begin{array}{l}\text { First } \\
\text { run }\end{array}$ & $\begin{array}{l}\text { Second } \\
\text { run }\end{array}$ & \\
\hline $\mathrm{Br}^{-}$ & 76.5 & 76.7 & $76.6 \pm 0.1$ & 23.5 & 23.3 & $23.4 \pm 0.1$ \\
\hline UR & 30.3 & 28.8 & $29.6 \pm 1.1$ & 69.7 & 71.2 & $70.5 \pm 1.1$ \\
\hline SRB & 36.4 & 38.0 & $37.2 \pm 1.1$ & 63.6 & 62.0 & $62.8 \pm 1.1$ \\
\hline Boscalid & 27.9 & 24.9 & $26.4 \pm 2.1$ & 72.1 & 75.1 & $73.6 \pm 2.1$ \\
\hline Penconazole & 17.3 & 20.7 & $19.0 \pm 2.4$ & 82.7 & 79.3 & $81.0 \pm 2.4$ \\
\hline Metazachlor & 7.5 & 7.4 & $7.5 \pm 0.1$ & 92.5 & 92.6 & $92.6 \pm 0.1$ \\
\hline Met-ESA & 6.1 & 5.4 & $5.8 \pm 0.5$ & - & - & - \\
\hline Met-OA & 0 & 0.8 & $0.4 \pm 0.6$ & - & - & - \\
\hline
\end{tabular}

Mean recovery and mean removal represent means \pm standard deviation.

for the removal of tracers and pesticides from the water in our system. Here, it should be noted that the adsorption of the solutes by the substrates could also involve their "temporary removal" from the water, as some of them may be released back into the soil solution. The physicochemical properties of the compounds have most likely been a determining factor for their dissipation. Vallée et al. (2014) found that a greater retention of pesticides in the soil was related to higher hydrophobic properties (low solubilities and high $K_{\text {oc }}$ values). Based on this assumption, we would have expected higher recoveries for metazachlor than for penconazole and boscalid, given its less hydrophobic character. However, unlike boscalid and penconazole, transformation processes played an important role in the dissipation of metazachlor, as demonstrated by the detection of its TPs. Conversely, given the greater persistence of boscalid and penconazole in the soil (DT 50 values of 484.4 and $117 \mathrm{~d}$, respectively), we would have anticipated higher recoveries of these solutes after the flushings. However, only $26.4 \%$ and $19 \%$ of boscalid and penconazole were recovered, respectively. Hence, we hypothesized that the cause of the low recoveries of boscalid and penconazole may have been their high sorption potential and possible plant uptake.

As for the tracers, $\mathrm{Br}^{-}$recovery was the largest (see Table 4), which was in agreement with its conservative character. The recovery of SRB was also high compared with the other solutes, presumably because this tracer was mostly subject to sorption processes and was more resistant to degradation and plant uptake. This behavior has already been reported in a recent study (Fernández-Pascual et al., 2018). The lowest recovery among the tracers was for UR. In this case, it was assumed that both retention and especially degrada- 


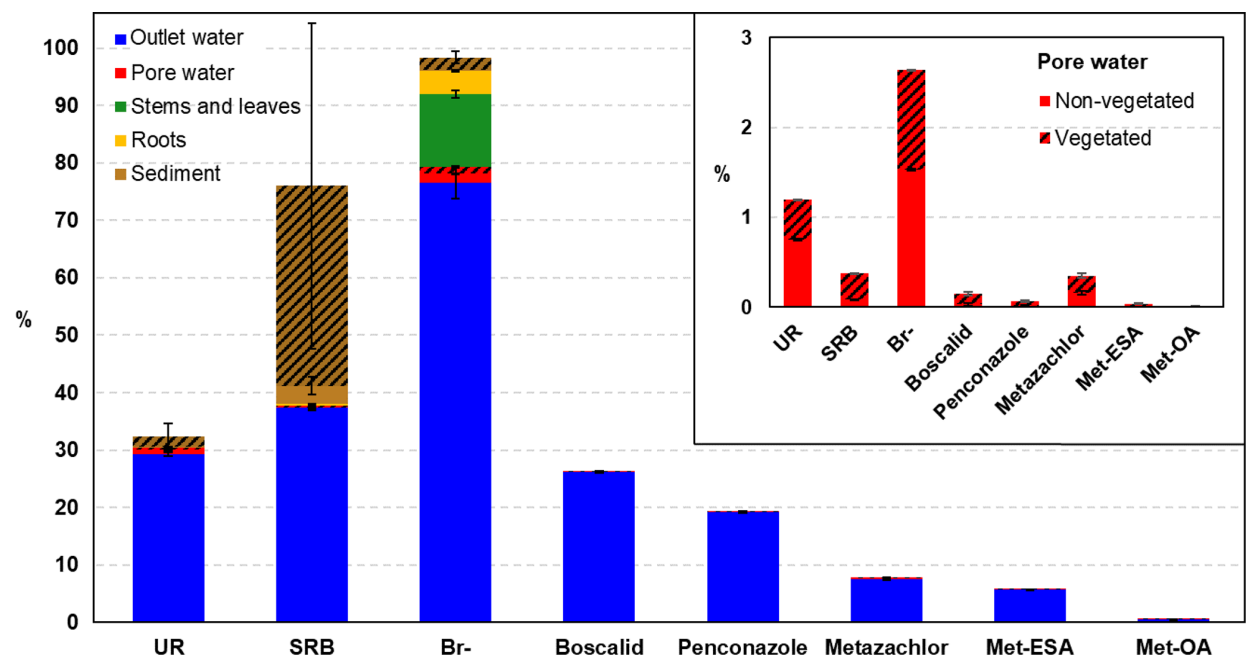

Figure 9. Final mass balance conducted at the end of the experiment in the different compartments. Note that the pesticides and their TPs could only be measured in the outlet and pore water compartments. The mass balance for the TPs was calculated according to the total amount of parent compound injected. The shaded area represents the percentage measured in the vegetated zone. The mass balance for the pore water compartment is detailed in the inset graph.

tion processes were involved in its dissipation. These results were in agreement with field studies performed in wetland systems, where recoveries for UR were lower than for SRB and were explained by a higher incidence of degradation processes (i.e., photodegradation) on UR dissipation (Passeport et al., 2010; Lange et al., 2011; Schuetz et al., 2012).

\subsection{Final mass balance}

The overall mass balance performed at the end of the experiment is shown in Fig. 9. $\mathrm{Br}^{-}$was almost fully recovered $(98.3 \%)$, whereas SRB and UR displayed lower recoveries (76\% and $32.4 \%$, respectively). These findings were similar to those of Maillard et al. (2016), who recovered 97.2, 43.3\% and $24.3 \%$ of $\mathrm{Br}^{-}$, SRB and UR, respectively, in their wetland experiment under batch conditions. Discrepancies with SRB were associated with the large uncertainty in the measurements performed in the sediment, which were caused by its heterogeneous distribution, as can be seen in Fig. S4. Indeed, almost $99 \%$ of the SRB measured in the vegetated area was located in the uppermost layer.

According to the different compartments, $\mathrm{Br}^{-}$and UR showed the highest recoveries in the outlet water, which highlighted their higher mobility. In contrast, SRB was mainly found in the sediment. These results pointed out the different behavior of the tracers when it comes to dissipation. As already evidenced by the breakthrough and cumulative recovery curves, $\mathrm{Br}^{-}$displayed the most conservative character, although some dissipation was observed via plant uptake (16.76\% of the total recovered). The main dissipation pathway of SRB was sorption, which was in agreement with the results of other studies (Lange et al., 2011; Durst et al., 2013; Maillard et al., 2016). UR, in contrast, displayed com- paratively lower recoveries, and based on the small amounts found in the sediment, sorption processes were not relevant for its dissipation. Thus, photodegradation and, to a lesser extent, biodegradation were most likely the major dissipation pathways for UR. Indeed, the contribution of (bio-)chemical transformation to UR dissipation has already been reported in other long-term studies (Maillard et al., 2016; FernándezPascual et al., 2018; Lange et al., 2018). Due to the likely adaptation of microorganisms to UR degradation after being exposed in the first run, we would have expected lower recovery rates in the second run (Käss, 1998). However, the final recovery values of UR were similar in both runs $(31.71 \%$ and $29.82 \%$ for the first and second runs, respectively). Hence, we hypothesized that other substrates for microbial degradation were present in the system and were preferentially utilized, limiting the degradation of alternative substrates such as UR. Photodegradation of UR was evidenced by the decrease in its concentration during saturation in the vegetated part (exposed to light) of the uppermost layer (see Fig. 4). In contrast, no decrease was observed in the part of the same layer that was not exposed to light. Differences were also observed between runs. While in the first run a decrease in the concentration of UR from 17.44 to $12.26 \mu \mathrm{g} \mathrm{L}^{-1}$ was detected, in the second run the values decreased from 26.45 to $9.62 \mu \mathrm{g} \mathrm{L}^{-1}$. Assuming first-order decay, we obtained degradation coefficients of 0.05 and $0.17 \mathrm{~d}^{-1}$, and half-life times of 13 and $4 \mathrm{~d}$ for the first and second runs, respectively. These values were comparatively lower than the half-life times reported in the literature, which are approximately $11 \mathrm{~h}$ (Leibundgut et al., 2009). However, natural light conditions could not be achieved in the laboratory and this could have limited UR photodegradation. The differences between the first and 
second runs were more difficult to explain, as, according to literature, the decay rate is inversely correlated with the tracer concentration (Leibundgut et al., 2009). The co-occurrence of photodegradation and microbial degradation could be a possible explanation for the higher decay rate obtained in the second run. However, other factors could not be excluded.

As for the pesticides, while the measurement of metazachlor TPs confirmed that biochemical transformation contributed to its dissipation, the transformation of boscalid and penconazole could not be proven. However, it could not be ruled out as the concentration of their metabolites may have been below the limit of quantification. However, considering the duration of the experiment $(62.5 \pm 2.12 \mathrm{~d}$ each run) and the $\mathrm{DT}_{50}$ values of boscalid and penconazole reported in the literature (Table 1), their transformation was probably minimal. Plant uptake, in contrast, could not be determined for the pesticides in the present study. Yet, it was assumed that it took place given the results of $\mathrm{Br}^{-}$and the findings of other investigations. For instance, Papaevangelou et al. (2017) demonstrated that high amounts of boscalid accumulated in the tissue of Phragmites australis in constructed wetlands, although adsorption was also an important process. The same plant species was shown to take up, translocate and metabolize tebuconazole (a triazole fungicide similar to penconazole) (Lv et al., 2017). Traces of metazachlor and its metabolites were also detected in the roots and stems of Glyceria maxima in wetland mesocosm experiments (Chen et al., 2017), although plant uptake was reported to play a negligible role in their removal. Other dissipation pathways, such as mineralization of the compounds to $\mathrm{CO}_{2}$ or volatilization from aqueous systems/soil water could not be ruled out. However, they were considered to be minimal according to literature (EFSA, 2008a, b). With this in mind, it can be concluded that retention played a fundamental role in our study (at least for boscalid and penconazole). Therefore, special attention should be paid to retention processes when assessing the mitigation capacities of strongly sorbing pesticides, such as boscalid and penconazole, in wetlands. In these systems the depletion of the sorption capacities will depend on both the concentration of the adsorbing substances and the number of sorption sites.

The contribution of vegetation to dissipation has also been evaluated in the final mass balance (Fig. 9a). Lower amounts of UR and $\mathrm{Br}^{-}$were recovered from the pore water of the vegetated zone compared with the non-vegetated area; however, the differences were not significant. Contrary to expectations, the largest amounts of pesticides and SRB were recovered from the pore water of the vegetated zone. However, these results supported the hypothesis of the promotion of transport towards the vegetated surface. Most of SRB was found sorbed in the sediment of the vegetated zone of the uppermost layer (Fig. S4), where the highest concentration of organic carbon was also measured. This may be explained by the susceptibility of SRB to sorption on nonpolar sorption sites of organic matter (Polat et al., 2011). Moreover, it has been recently demonstrated that SRB has high sorption affinity for litter in wetlands (Dollinger et al., 2017). Thus, the presence of dead leaves and decaying plant residues in the uppermost layer probably enhanced the sorption of SRB.

\subsection{Implications for pesticide mitigation in wetland systems}

The replicated conditions in our experiment may resemble those of a groundwater-fed wetland that undergoes wet-dry cycles. In principle, we can expect to obtain analogous results in natural systems if similar conditions to those of our study are met. If we compare the characteristics of our experiment (see Table 2) with those of other wetland investigations (e.g., Catallo, 1999; Seybold et al., 2002; Maillard et al., 2011; Gardiner and James, 2012; Passeport et al., 2013; Vallée et al., 2016; Gikas et al., 2018), we find similar values in terms of sediment texture (values ranging from 4 to $89.5,6.2$ to 55 and 3.8 to 44 for the percentage of sand, silt and clay, respectively), sediment $\mathrm{pH}$ (values ranging from 6 to 8), conductivity (values ranging from 0.45 to $0.9 \mathrm{dS} \mathrm{m}^{-1}$ ) and redox potential (values ranging from -500 to $+500 \mathrm{mV}$ ). Nevertheless, there are some discrepancies regarding the organic carbon content (values ranging from $2.6 \%$ to $32.7 \%$ ) and the mean residence time (values ranging from 0.5 to $8 \mathrm{~d}$ ). In this case, the values of our experiment were either below (for the organic carbon content) or above average (mean residence time). However, the overall removal rates obtained in our experiment (see Table 7) were within the same range as those of other wetland studies. For instance, Vallée et al. (2015) found that the removal rates of boscalid in two pilot-scale wetlands ranged from $38 \%$ to $67 \%$, whereas Gikas et al. (2018) obtained removal rates for S-metolachlor (pesticide from the same group as metazachlor) that reached up to $92.6 \%$ in a constructed wetland planted with Phragmites australis. Other authors have reported removal rates of between $45 \%$ and $90 \%$ for tebuconazole in wetland systems (Passeport et al., 2013; Tournebize et al., 2013).

A possible explanation for the high removal rates obtained in our experiment could be the fact that contact of solutes with the medium was promoted due to a long period of stagnation (i.e., about 2 months in each run). In this regard, a recent study performed by Gaullier et al. (2019) reported almost total mitigation of pesticides and their TPs during stagnation (over 50 d) in constructed wetlands. According to these findings, promoting solute contact with the medium through long periods of stagnation may be important when constructing engineered systems designed to remove contaminants from the water.

Overall, these observations highlight the significance of certain factors in the removal of pesticides, namely the presence of adequate vegetation, suitable matrix materials, long residence times, low flow rates and intermittent flow conditions, among others (Vymazal and Březinová, 2015; Liu et al., 2018). When these factors are promoted, the removal 
rates tend to increase; therefore, the mitigation capacities of constructed wetlands also increase. However, as previously stated, the physicochemical properties of the compounds are a decisive factor in their elimination.

\subsection{Potential of hydrological tracers to evaluate transport and dissipation processes of pesticides in constructed wetlands}

In view of the results obtained in the present study, some conclusions could be drawn regarding the use of $\mathrm{Br}^{-}$, SRB and UR to evaluate transport and dissipation processes of pesticides in constructed wetlands. In particular, we have corroborated that $\mathrm{Br}^{-}$can be used to elucidate nonreactive transport of solutes, as already reported in the literature (Lin et al., 2003; Małoszewski et al., 2006). But it can also be applied to identify plant uptake (Xu et al., 2004), although to a lesser extent. SRB, has frequently been used to identify sorption processes of pesticides in wetland systems (Passeport et al., 2010; Lange et al., 2011; Schuetz et al., 2012). However, its special sorptive character makes it difficult to compare with a specific type of pesticide. Some authors (e.g., Dollinger et al., 2017) have stated that SRB could be used as a good proxy for hydrophilic and strongly sorbing pesticides, while others (e.g., Lange et al., 2018) proved that the same tracer closely mimicked the gradual recession of a moderately hydrophobic pesticide in the topsoil of an agricultural field. Our results demonstrated that SRB can serve to approximate the behavior of boscalid and penconazole (moderately and highly hydrophobic pesticides, respectively) in terms of retention and retardation in the pore water and in the water at the outlet when the constructed wetland is repeatedly flushed. However, it may not be suitable to evaluate overall recoveries of such pesticides at the outlet. In this context, lower amounts of boscalid and penconazole may be recovered compared with SRB due to the high sorption potential of the pesticides and their susceptibility to being taken up by plants. Regarding UR, in terms of transport, our results suggested that it may illustrate the behavior of mobile and nonpersistent pesticides, such as metazachlor, well. This is in agreement with the findings of other studies (Durst et al., 2013; Maillard et al., 2016; Torrentó et al., 2017). At the same time, our results have underlined that UR may experience not only photodegradation, but also biodegradation, which is consistent with the results of recent investigations (Maillard et al., 2016; Lange et al., 2018; Fernández-Pascual et al., 2018). However, UR biodegradation might be limited in the presence of preferred substrates for microorganisms. In any case, it should be noted that the conclusions presented here are only valid if these tracers are used in studies under analogous conditions to those of our experiment. That is, constructed wetlands that undergo long periods of stagnation ( $>2$ months) with drying periods in between, sorbing material with low organic carbon content, similar vegetation and subject to analogous dominant processes.

\section{Conclusions}

The present study introduces a new approach that combines the use of hydrological tracers with different sorptive and reactive properties and high vertical resolution sampling and monitoring to explore transport and dissipation processes of reactive compounds (i.e., pesticides) inside a wetland system. By comparing tracers with selected pesticides, valuable hints about dominant transport vectors and main dissipation pathways have been collected.

Breakthrough curves obtained at different sampling depths suggested that solute transport was favored towards the vegetated uppermost layer, probably due to lateral transport at or near the surface and/or a possible shortcut effect produced by the roots. However, other mechanisms not necessarily related to plants (e.g., fingering) could not be ruled out. Conversely, solute transport was retarded in the middle layers, most likely due to the presence of water-filled pores before the injection and low pore connectivity in the vicinity of the sampling ports. Spatial and temporal variability of transport and dissipation processes were associated with the conditions prior to injection, the way the solutes entered the system, the presence of plants and the promotion of aeration during the drying phase. The strong positive correlation found between $\mathrm{Br}^{-}$, UR and metazachlor highlighted the predominance of transport processes for these compounds. By contrast, SRB, boscalid and penconazole most likely experienced sorption as evidenced by their absence in the middle layers, rapid decrease in their concentrations after the injection and gradual increase in accumulated mass recovery during the flushing phase. However, the lower final recoveries of boscalid and penconazole compared with SRB suggested a greater contribution of retention and plant uptake in their dissipation.

The overall tracer mass balance allowed us to identify three dissipation pathways: sorption, transformation and plant uptake. While $\mathrm{Br}^{-}$was almost fully recovered (98.3\%), SRB and UR displayed lower recovery rates (76\% and $32.4 \%$, respectively). These results were explained by the greater occurrence of sorptive processes in SRB and transformation in UR. The detection of metazachlor TPs, namely met-ESA and met-OA, demonstrated that biochemical transformation played an important role in metazachlor dissipation, whereas no TPs for boscalid and penconazole were found. Yet, their transformation could not be ruled out in the present study. Likewise, plant uptake of pesticides could not be confirmed but it was assumed that it took place throughout the experiment.

Our findings pointed out that the presence of plants and the alternation of different hydrological conditions (saturation and drying periods) may favor dissipation processes. The combination of these factors in combination with others (e.g., suitable matrix materials and long residence times) could increase the mitigation capacities of wetland systems. However, plants might also be involved in the creation of 
preferential flow paths with the consequent risk of rapid transport of contaminants.

Overall, the complexity of the processes that take place inside constructed wetlands and the lack of sufficient data on both temporal and spatial scales highlights the need to adopt new methods to fully understand the behavior of pollutants in these systems. The application of a multi-tracer approach coupled with high vertical resolution sampling and monitoring may assist in unveiling internal mechanisms that dominate transport and dissipation of contaminants. However, further experiments need to be carried out, especially under field conditions combined with modeling.

Data availability. The underlying data used in this analysis are available as supplementary information from the "Technical report on the design and construction of a laboratory-scale experimental set-up" article, which was published online as Series Paper 4 in Freiburg HydroNotes: http://www.hydrology.uni-freiburg. de/publika/hydronotes/ (Fernández-Pascual and Lange, 2019).

Supplement. The supplement related to this article is available online at: https://doi.org/10.5194/hess-24-41-2020-supplement.

Author contributions. EFP developed ideas, collected the data, performed the analysis and wrote the paper. MB helped with data analysis and developing ideas. BH contributed to the data analysis. JL contributed to the development of the main ideas, the preparation of the paper and the data analysis strategy. All authors read and approved the final paper.

Competing interests. The authors declare that they have no conflict of interest.

Acknowledgements. The authors wish to acknowledge Emil Blattmann and Britta Kattenstroth for their help with the construction of the experimental setup as well as Barbara Herbstritt, Jens Robertson, Felix Zimmermann and Maria Martin Pérez for sampling and analytical support. We would also like to thank Marit van Tiel and Sunanth Venkateshwaran for constructive criticism of the paper, and Christine Stumpp for her valuable advice and contribution to the design of the sampling setup.

Financial support. This research has been supported by the German Federal Ministry for Education and Research (BMBF; grant no. 02WRM1366B). The article processing charge was funded by the German Research Foundation (DFG) and the University of Freiburg as part of the Open Access Publishing funding program.

Review statement. This paper was edited by Erwin Zehe and reviewed by three anonymous referees.

\section{References}

Bard, A. J., Parsons, R., and Jordan, J.: Standard Potentials in Aqueous Solution, Marcel Dekker Inc., New York, 1985.

Bouldin, J. L., Farris, J. L., Moore, M. T., Smith Jr., S., Stephens, W. W., and Cooper, C. M.: Evaluated fate and effects of atrazine and lambda-cyhalothrin in vegetated and unvegetated microcosms, Environ. Toxicol.: Int. J., 20, 487-498, 2005.

Brix, H.: Do macrophytes play a role in constructed treatment wetlands?, Water Sci. Technol., 35, 11-17, 1997.

Casado, J., Brigden, K., Santillo, D., and Johnston, P.: Screening of pesticides and veterinary drugs in small streams in the European Union by liquid chromatography high resolution mass spectrometry, Sci. Total Environ., 670, 1204-1225, 2019.

Catallo, W. J: Hourly and Daily Variation of Sediment Redox Potential in Tidal Wetland Sediments, Geological Survey, Reston, VA, 1999.

ChemID database: https://chem.nlm.nih.gov/chemidplus/, last access: 14 May 2017.

Chen, Z., Chen, Y., Vymazal, J., Kule, L., and Koželuh, M.: Dynamics of chloroacetanilide herbicides in various types of mesocosm wetlands, Sci. Total Environ., 577, 386-394, 2017.

Dollinger, J., Dagès, C., and Voltz, M.: Using fluorescent dyes as proxies to study herbicide removal by sorption in buffer zones, Environ. Sci. Poll. Res., 24, 11752-11763, 2017.

Durst, R., Imfeld, G., and Lange, J.: Transport of pesticides and artificial tracers in vertical-flow lab-scale wetlands, Water Resour. Res., 49, 554-564, 2013.

EFSA - European Food Safety Authority: Conclusion regarding the peer review of the pesticide risk assessment of the active substance metazachlor, EFSA J., 6, 145r, 2008a.

EFSA - European Food Safety Authority: Conclusion regarding the peer review of the pesticide risk assessment of the active substance penconazole, EFSA J., 6, 175r, 2008b.

Eurostat: Agri-environmental indicator-pesticide pollution of water, Statistics explained, European Commission, available at: https: //ec.europa.eu/eurostat/statistics-explained/index.php/Archive: Agri-environmental_indicator_pesticide_pollution_of_water (last access: 1 October 2018), 2012.

Fan, J., Zhang, B., Zhang, J., Ngo, H. H., Guo, W., Liu, F., Guo, Y., and $\mathrm{Wu}, \mathrm{H} .:$ Intermittent aeration strategy to enhance organics and nitrogen removal in subsurface flow constructed wetlands, Bioresour. Technol., 141, 117-122, 2013.

Fernández-Pascual, E. and Lange, J.: Technical report on the design and construction of a laboratory-scale experimental set-up. A model constructed wetland system designed to perform high vertical-resolution sampling and monitoring, available at: http: //www.hydrology.uni-freiburg.de/publika/hydronotes/, last access: 20 December 2019.

Fernández-Pascual, E., Zaman, S., Bork, M., Lang, F., and Lange, J.: Long-term mesocosm experiments to investigate degradation of fluorescent tracers, J. Hydrol., 2, 100014, https://doi.org/10.1016/j.hydroa.2018.100014, 2018.

Gardiner, D. T. and James, S.: Wet soil redox chemistry as affected by organic matter and nitrate, Am. J. Clim. Change, 1, 205-209, 2012.

Gaullier, C., Baran, N., Dousset, S., Devau, N., Billet, D., Kitzinger, G., and Coisy, E.: Wetland hydrodynamics and mitigation of pesticides and their metabolites at pilot-scale, Ecol. Eng., 136, 185192, 2019. 
Ghestem, M., Sidle, R. C., and Stokes, A.: The influence of plant root systems on subsurface flow: implications for slope stability, Bioscience, 61, 869-879, 2011.

Gikas, G. D., Vryzas, Z., and Tsihrintzis, V. A.: S-metolachlor herbicide removal in pilot-scale horizontal subsurface flow constructed wetlands, Chem. Eng. J., 339, 108-116, 2018.

Gutowski, L., Olsson, O., Lange, J., and Kümmerer, K.: Photolytic transformation products and biological stability of the hydrological tracer Uranine, Sci. Total Environ., 533, 446-453, 2015.

Hofmann, K.: Wachstumsverhalten von Schilf (Phragmites australis (Cav.) Trin. ex Steudel), in: klärschlammbeschickten Filterbeeten, Arch. Hydrobiol., 107, 385-409, 1986.

Holden, J.: Piping and woody plants in peatlands: Cause or effect?, Water Resour. Res., 41, W06009, https://doi.org/10.1029/2004WR003909, 2005.

Joseph, G.: Determination of sodium monofluoroacetate in dairy powders by liquid chromatography tandem mass spectrometry (LC-MS/MS): First Action 2015.02, J. AOAC Int., 98, 11211126, 2015.

Käss, W., Behrens, H., and Behrens, H.: Tracing technique in geohydrology, Balkema, Rotterdam, the Netherlands, 581 pp., 1998.

Karpuzcu, M. E., Sedlak, D. L., and Stringfellow, W. T.: Biotransformation of chlorpyrifos in riparian wetlands in agricultural watersheds: Implications for wetland management, J. Hazard. Mater., 244, 111-120, 2013.

Kasnavia, T., Vu, D., and Sabatini, D. A.: Fluorescent dye and media properties affecting sorption and tracer selection, Groundwater, 37, 376-381, 1999.

Kolpin, D. W., Schnoebelen, D. J., and Thurman, E. M.: Degradates provide insight to spatial and temporal trends of herbicides in ground water, Groundwater, 42, 601-608, 2004.

Lange, J., Schuetz, T., Gregoire, C., Elsässer, D., Schulz, R., Passeport, E., and Tournebize, J.: Multi-tracer experiments to characterise contaminant mitigation capacities for different types of artificial wetlands, Int. J. Environ. Anal. Chem., 91, 768-785, 2011.

Lange, J., Olsson, O., Sweeney, B., Herbstritt, B., Reich, M., Alvarez-Zaldivar, P., Payraudeau, S., and Imfeld, G.: Fluorescent tracers to evaluate pesticide dissipation and transformation in agricultural soils, Sci. Total Environ., 619, 1682-1689, 2018.

Leibundgut, C., Maloszewski, P., and Külls, C.: Environmental tracers, in: Tracers in Hydrology, John Wiley \& Sons, Ltd., Chichester, UK, 13-56, 2009.

Lin, A. Y. C., Debroux, J. F., Cunningham, J. A., and Reinhard, M.: Comparison of rhodamine WT and bromide in the determination of hydraulic characteristics of constructed wetlands, Ecol. Eng., 20, 75-88, 2003.

Liu, T., Xu, S., Lu, S., Qin, P., Bi, B., Ding, H., Liu, Y., Guo, X., and Liu, X.: A review on removal of organophosphorus pesticides in constructed wetland: performance, mechanism and influencing factors, Sci. Total Environ., 651, 2247-2268, https://doi.org/10.1016/j.scitotenv.2018.10.087, 2018.

Long, R., Gan, J., and Nett, M.: Pesticide choice: Best management practice (BMP) for protecting surface water quality in agriculture, University of California, Division of Agriculture and Natural Resources, 8161, https://doi.org/10.3733/ucanr.8161, 2005.

Lv, T., Carvalho, P. N., Bollmann, U. E., Arias, C. A., Brix, H., and Bester, K.: Enantioselective uptake, translocation and degrada- tion of the chiral pesticides tebuconazole and imazalil by Phragmites australis, Environ. Pollut., 229, 362-370, 2017.

Maillard, E., Payraudeau, S., Faivre, E., Grégoire, C., Gangloff, S., and Imfeld, G.: Removal of pesticide mixtures in a stormwater wetland collecting runoff from a vineyard catchment, Sci. Total Environ., 409, 2317-2324, 2011.

Maillard, E., Lange, J., Schreiber, S., Dollinger, J., Herbstritt, B., Millet, M., and Imfeld, G.: Dissipation of hydrological tracers and the herbicide S-metolachlor in batch and continuous-flow wetlands, Chemosphere, 144, 2489-2496, 2016.

Małoszewski, P., Wachniew, P., and Czupryński, P.: Study of hydraulic parameters in heterogeneous gravel beds: Constructed wetland in Nowa Słupia (Poland), J. Hydrol., 331, 630-642, 2006.

Mamy, L., Barriuso, E., and Gabrielle, B.: Environmental fate of herbicides trifluralin, metazachlor, metamitron and sulcotrione compared with that of glyphosate, a substitute broad spectrum herbicide for different glyphosate-resistant crops, Pest Manage. Sci., 61, 905-916, 2005.

Martin, A., Margoum, C., Jolivet, A., Assoumani, A., El Moujahid, B., Randon, J., and Coquery, M.: Calibration of silicone rubber rods as passive samplers for pesticides at two different flow velocities: Modeling of sampling rates under water boundary layer and polymer control, Environ. Toxicol. Chem., 37, 1208-1218, 2018.

McMahon, P. B., Dennehy, K. F., Michel, R. L., Sophocleous, M. A., Ellett, K. M., and Hurlbut, D. B.: Water movement through thick unsaturated zones overlying the central High Plains aquifer, southwestern Kansas, 2000-2001, USGS WaterResources Investigations Report, vol. 3, no. 2003-4171, 32 pp. https://doi.org/10.3133/wri034171, 2003.

Mehra, O. P. Jackson, M. L.: Iron oxide removal from soils and clays by a dithionite-citrate system buffered with sodium bicarbonate, in: Clays and Clay Minerals, vol 5, Proceedings of the Seventh National Conference on Clays and Clay Minerals, 20 23 October 1958, Washington, D.C., USA, 317-327, 1960.

Müller, K., Bach, M., Hartmann, H., Spiteller, M., and Frede, H. G.: Point-and nonpoint-source pesticide contamination in the Zwester Ohm catchment, Germany, J. Environ. Qual., 31, 309318, 2002.

Nimmo, J. R.: Preferential flow occurs in unsaturated conditions, Hydrol. Process., 26, 786-789, 2012.

Ong, S. A., Uchiyama, K., Inadama, D., Ishida, Y., and Yamagiwa, K.: Performance evaluation of laboratory scale up-flow constructed wetlands with different designs and emergent plants, Bioresour. Technol., 101, 7239-7244, 2010.

Papaevangelou, V. A., Gikas, G. D., Vryzas, Z., and Tsihrintzis, V. A.: Treatment of agricultural equipment rinsing water containing a fungicide in pilot-scale horizontal subsurface flow constructed wetlands, Ecol. Eng., 101, 193-200, 2017.

Passeport, E., Tournebize, J., Jankowfsky, S., Prömse, B., Chaumont, C., Coquet, Y., and Lange, J.: Artificial wetland and forest buffer zone: hydraulic and tracer characterization, Vadose Zone J., 9, 73-84, 2010.

Passeport, E., Tournebize, J., Chaumont, C., Guenne, A., and Coquet, Y.: Pesticide contamination interception strategy and removal efficiency in forest buffer and artificial wetland in a tiledrained agricultural watershed, Chemosphere, 91, 1289-1296, 2013. 
Petticrew, E. L. and Kalff, J.: Water flow and clay retention in submerged macrophyte beds, Can. J. Fish. Aquat. Sci., 49, 24832489, 1992.

Polat, B. E., Lin, S., Mendenhall, J. D., VanVeller, B., Langer, R., and Blankschtein, D.: Experimental and molecular dynamics investigation into the amphiphilic nature of sulforhodamine $\mathrm{B}, \mathrm{J}$. Phys. Chem. B, 115, 1394-1402, 2011.

Reemtsma, T., Alder, L., and Banasiak, U.: Emerging pesticide metabolites in groundwater and surface water as determined by the application of a multimethod for 150 pesticide metabolites, Water Res., 47, 5535-5545, 2013.

Sabatini, D. A.: Sorption and intraparticle diffusion of fluorescent dyes with consolidated aquifer media, Groundwater, 38, 651$656,2000$.

Schmitt, G. and Herbold, M.: DINTEST Version 2003, Institut für Rechtsmedizin und Verkehrsmedizin, Universitätsklinikum Heidelberg, Heidelberg, Germany, 2003.

Schuetz, T., Weiler, M., and Lange, J.: Multitracer assessment of wetland succession: effects on conservative and nonconservative transport processes, Water Resour. Res., 48, W06538, https://doi.org/10.1029/2011WR011292, 2012.

Seybold, C. A., Mersie, W., Huang, J., and McNamee, C.: Soil redox, $\mathrm{pH}$, temperature, and water-table patterns of a freshwater tidal wetland, Wetlands, 22, 149-158, 2002.

Smart, P. L. and Laidlaw, I. M. S.: An evaluation of some fluorescent dyes for water tracing, Water Resour. Res., 13, 15-33, 1977.

Stehle, S. and Schulz, R.: Agricultural insecticides threaten surface waters at the global scale, P. Natl. Acad. Sci. USA, 112, 57505755, 2015.

Torrentó, C., Prasuhn, V., Spiess, E., Ponsin, V., Melsbach, A., Lihl, C., Glauser, G., Hofstetter, T. B., Elsner, M., and Hunkeler, D.: Adsorbing vs. nonadsorbing tracers for assessing pesticide transport in arable soils, Vadose Zone J., 17, https://doi.org/10.2136/vzj2017.01.0033, 2017.

Tournebize, J., Passeport, E., Chaumont, C., Fesneau, C., Guenne, A., and Vincent, B.: Pesticide de-contamination of surface waters as a wetland ecosystem service in agricultural landscapes, Ecol. Eng., 56, 51-59, 2013.
University of Hertfordshire: PPDB: Pesticide properties database, Hertfordshire, 2010.

Vallée, R., Dousset, S., Billet, D., and Benoit, M.: Sorption of selected pesticides on soils, sediment and straw from a constructed agricultural drainage ditch or pond, Environ. Sci. Poll. Res., 21, 4895-4905, 2014.

Vallée, R., Dousset, S., and Billet, D.: Water residence time and pesticide removal in pilot-scale wetlands, Ecol. Eng., 85, 76-84, 2015.

Vallée, R., Dousset, S., and Billet, D.: Influence of substrate water saturation on pesticide dissipation in constructed wetlands, Environ. Sci. Poll. Res., 23, 109-119, 2016.

von der Ohe, P. C., Dulio, V., Slobodnik, J., De Deckere, E., Kühne, R., Ebert, R. U., Ginebreda, A., De Cooman, W., Schüürmann, G., and Brack, W.: A new risk assessment approach for the prioritization of 500 classical and emerging organic microcontaminants as potential river basin specific pollutants under the European Water Framework Directive, Sci. Total Environ., 409, 2064-2077, 2011.

Vorenhout, M., van der Geest, H. G., and Hunting, E. R.: An improved datalogger and novel probes for continuous redox measurements in wetlands, Int. J. Environ. Anal. Chem., 91, 801810, 2011.

Vymazal, J.: Horizontal sub-surface flow and hybrid constructed wetlands systems for wastewater treatment, Ecol. Eng., 25, 478490, 2005.

Vymazal, J. and Březinová, T.: The use of constructed wetlands for removal of pesticides from agricultural runoff and drainage: a review, Environ. Int., 75, 11-20, 2015.

Wernli, H. R.: Einführung in die Tracerhydrologie: hydrologisches Praktikum, Geographisches Institut Univ., Bern, 2009.

Whitmer, S., Baker, L., and Wass, R.: Loss of bromide in a wetland tracer experiment, J. Environ. Qual., 29, 2043-2045, 2000.

Xu, S., Leri, A. C., Myneni, S. C., and Jaffé, P. R.: Uptake of bromide by two wetland plants (Typha latifolia L. and Phragmites australis (Cav.) Trin. ex Steud), Environ. Sci. Technol., 38, 56425648, 2004. 